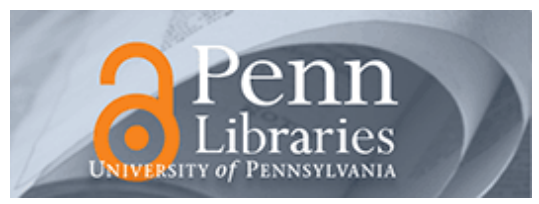

University of Pennsylvania

ScholarlyCommons

January 2008

\title{
An Investigation of Classroom Situational Dimensions of Emotional and Behavioral Adjustment and Cognitive and Social Outcomes for Head Start Children
}

\author{
Rebecca J. Bulotsky-Shearer \\ Erikson Institute \\ John Fantuzzo \\ University of Pennsylvania, JOHNF@GSE.UPENN.EDU \\ Paul A. McDermott \\ University of Pennsylvania
}

Follow this and additional works at: https://repository.upenn.edu/gse_pubs

\section{Recommended Citation}

Bulotsky-Shearer, R. J., Fantuzzo, J., \& McDermott, P. A. (2008). An Investigation of Classroom Situational Dimensions of Emotional and Behavioral Adjustment and Cognitive and Social Outcomes for Head Start Children. Retrieved from https://repository.upenn.edu/gse_pubs/152

\footnotetext{
Postprint version. Published in Developmental Psychology, Volume 44, Issue 1, January 2008, pages 139-154. Publisher URL: http://dx.doi.org/http://psycnet.apa.org/ index.cfm?fa=main. showContent\&id=2007-19851-015\&view=fulltext

This paper is posted at ScholarlyCommons. https://repository.upenn.edu/gse_pubs/152

For more information, please contact repository@pobox.upenn.edu.
} 


\title{
An Investigation of Classroom Situational Dimensions of Emotional and Behavioral Adjustment and Cognitive and Social Outcomes for Head Start Children
}

\author{
Abstract \\ This study employed a developmental-ecological approach to investigate the relationship across the \\ school year between early problems in preschool classroom situations and a comprehensive set of \\ readiness competencies for urban, low-income children. Study I identified three reliable and unique \\ underlying classroom situational dimensions where behavior problems occurred: Structured Learning, \\ Peer Interaction, and Teacher Interaction situations. Boys and younger children evidenced more \\ problematic behavior across all situations. Study II investigated the relationship between early problems \\ in the situations and readiness outcomes. Early situational difficulties uniquely and differentially predicted \\ lower peer social and classroom learning outcomes. In combination, both the type of behavior problem \\ (what) and the situational problem (where) explained greater variance in the prediction of readiness \\ outcomes, contributing to a more comprehensive understanding of developmental trajectories.
}

\section{Comments}

Postprint version. Published in Developmental Psychology, Volume 44, Issue 1, January 2008, pages 139-154.

Publisher URL: http://dx.doi.org/http://psycnet.apa.org/

index.cfm?fa=main. showContent\&id=2007-19851-015\&view=fulltext 
Running head: PRESCHOOL CLASSROOM SITUATIONS AND ADJUSTMENT

An Investigation of Classroom Situational Dimensions of Emotional and Behavioral Adjustment and Cognitive and Social Outcomes for Head Start Children

\author{
Rebecca J. Bulotsky-Shearer \\ Erikson Institute \\ John W. Fantuzzo \\ Paul A. McDermott \\ University of Pennsylvania
}

Final version published in DEVELOPMENTAL PSYCHOLOGY 44 (1): 139-154 JAN 2008 
An Investigation of Classroom Situational Dimensions of Emotional and Behavioral Adjustment and Cognitive and Social Outcomes for Head Start Children

\begin{abstract}
This study employed a developmental-ecological approach to investigate the relationship across the school year between early problems in preschool classroom situations and a comprehensive set of readiness competencies for urban, low-income children. Study I identified three reliable and unique underlying classroom situational dimensions where behavior problems occurred: Structured Learning, Peer Interaction, and Teacher Interaction situations. Boys and younger children evidenced more problematic behavior across all situations. Study II investigated the relationship between early problems in the situations and readiness outcomes. Early situational difficulties uniquely and differentially predicted lower peer social and classroom learning outcomes. In combination, both the type of behavior problem (what) and the situational problem (where) explained greater variance in the prediction of readiness outcomes, contributing to a more comprehensive understanding of developmental trajectories.
\end{abstract}


An Investigation of Classroom Situational Dimensions of Emotional and Behavioral Adjustment and Cognitive and Social Outcomes for Head Start Children

Much national attention has been paid to the important contribution of emotional and behavioral adjustment to young children's school success (Raver \& Knitzer, 2002). A recent report from the National Academy of Sciences emphasizes the compromising effects of social, regulatory and emotional impairments on children's early adaptation to normal developmental challenges, such as school entry (Shonkoff \& Phillips, 2000). In addition, empirical research suggests that children exhibiting emotional and behavioral problems are likely to demonstrate a host of difficulties within the preschool classroom that interfere with learning and developing peer relationships (Belsky \& MacKinnon, 1994; Entwisle \& Alexander, 1993). These children are less likely to be socially and academically ready for kindergarten (Huffman, Mehlinger, \& Kerivan, 2000).

A large body of empirical literature documents the influence of early risk factors on children's emotional and behavioral adjustment. Children living in poverty, particularly in densely populated urban areas, are disproportionately exposed to the repeated and long-term stressors associated with poverty, such as malnutrition, inadequate housing, community violence, crime and parental isolation (Garbarino, 1995; McCloyd, 1998). Exposure to these multiple risks during critical periods of development increases the likelihood that young children will face emotional and behavioral challenges as they adjust to school (Duncan \& Brooks-Gunn, 1997; Lavigne et al., 1996; Qi \& Kaiser, 2003; Raver, 2002).

Quality early childhood educational experiences are identified as important interventions for low-income, urban-residing children with emotional and behavioral needs (Barnett, 1998; NICHD Early Child Care Research Network, 2000; Peisner-Feinberg, Burchinal, Clifford, 
Culkin, Howes, Kagan, et al., 2001). Key to intervention within early educational environments is understanding problem behavior in the context of multiple classroom situational demands (Friedman \& Wachs, 1999; Jensen \& Hoagwood, 1997; Sameroff \& Fiese, 2000). The diverse learning opportunities within a preschool classroom contain distinct cognitive and social demands that require complex behavior and can increase the likelihood of behavior problems (Kontos \& Keyes, 1999). Early interventions that identify challenging classroom situational demands for preschool children can facilitate successful adjustment to school (Campbell, 2002). A developmental-ecological theoretical perspective provides a framework to examine emotional and behavioral problems as a function of preschool classroom learning demands. This model recognizes: (a) both child-level and proximal system influences on adaptive and maladaptive behavior, and (b) the development of emotional and behavioral problems as a function of the dynamic transaction between situational demands and child capacities over time (Sameroff, 1975; Sameroff \& Fiese, 2000; Sroufe, 1997).

According to this model, there are multiple natural environments that influence child behavior (Belsky, 1993; Bronfenbrenner, 1979; Wachs, 1992). The most proximal influence, the microsystem, exerts the greatest influence on children's behavior. The processes through which this system influences children are seen as bi-directional over time. Not only are children influenced by the environment, but the environment is responsive to individual characteristics of children as well (Bronfenbrenner \& Morris, 1998). These child-level characteristics, or ontogenetic influences (e.g., biological or developmental factors), are used to actively organize and structure children's experiences within environmental settings (Sameroff \& Chandler, 1975).

The preschool classroom is an important microsystem influence for young children (Bronfenbrenner \& Morris, 1998; Friedman \& Wachs, 1999). Various interdependent 
subsystems within the preschool classroom are hypothesized to influence children in a complex, dynamic manner - each with their own set of unique demands and expectations for behavior (Carta, Sainato, \& Greenwood, 1988; McEvoy, 1990; Stollar \& Dye Collins, 1994). Each situation or learning opportunity in the classroom contains distinct cognitive and social demands that require a repertoire of complex skills and behavior. Teacher and peer social expectations, classroom rules, attention to tasks, appropriate play, and the establishment of friendship patterns are examples of some of these preschool classroom demands (Feil, Severson, \& Walker, 1995). Child problem behavior develops as a function of the dynamic transactions between ontogenetic capacities and these multiple classroom demands (Cicchetti \& Sroufe, 2000; Cicchetti \& Toth, 1997). Children master tasks and demands based on their individual resources and past experiences. Problem behavior results when the demands of the situation do not match child capacities (Goldstein, 1995). Classroom behavioral difficulties are seen arising from a mismatch between the child's ontogenetic capacities (e.g., self-regulation, attention, cognitive skill or motivation), prior history of adaptation, and the academic (or social) demands of learning situations (McEvoy \& Welker, 2000).

In accord with this model, empirical studies are needed that investigate these complex and dynamic developmental processes in order to inform developmentally appropriate, classroom-based early intervention strategies for low-income, preschool children. Studies are needed that: (a) identify multiple classroom situational influences on child behavioral adaptation, and (b) examine the unique and combined influence of both classroom situational and child-level behavioral problems on early learning and social outcomes. This investigation would provide information about both child-level behavioral needs as well as classroom contextual demands that are designed to stimulate cognitive and social development. 
Unfortunately, the empirical literature provides few studies of preschool behavior with adequate methods to capture both dynamic classroom situational processes and child-level behavioral problems over time. Typical classroom research has either studied the contribution of global environmental quality indicators (e.g., Cassidy, Hestenes, Hegde, Hestenes, \& Mims, 2005; Harms, Clifford, \& Cryer, 1998; Perlman, Zellman, \& Le, 2004) or types of behavior problems (syndromes) assessed via frequency checklists of clinical symptoms [e.g., Aggressive Behavior or Anxious/Depressed Behavior (CBCL; Achenbach, 1991)]. While these studies provide important information about global classroom quality and child-level types of behavior problems, they are limited by the static picture they provide and the tendency to attribute types of behavior problems to a "stable deficit" within the child rather than considering the cultural and situational context of problem behavior (Cicchetti \& Toth, 1997; Fantuzzo \& Mohr, 2000; Jensen \& Hoagwood, 1997; Sherrod, 1999). From a developmental-ecological point of view, this limits understanding of children whose behavior varies considerably across different settings and situational demands and does little to advance our understanding of how and where to strategically intervene in the classroom for struggling children [e.g., how and where the classroom environment could be modified to support more adaptive behavior and facilitate learning (Goldstein, 1995; McEvoy \& Welker, 2000; Merrell, 1999)].

Promisingly, an alternative empirical approach has been developed that examines both traditional types of behavior problems within the classroom as well as types of classroom situations where problems occur. McDermott (1993) conceptualized a method for capturing both sets of information simultaneously and studied their unique and combined contribution to social and academic outcomes for elementary school children. In dialogue with teachers, McDermott, Marston \& Stott (1993) developed a comprehensive set of 156 routinely observed, adaptive and 
maladaptive behaviors presented within the context of 29 typical classroom situations involving social, cognitive and physical development. These included children's adjustment to authority, peers, smaller or weaker children, play, school work, and confrontation [Adjustment Scales for Children and Adolescents (ASCA; McDermott, 1993)].

A series of studies employing multivariate factor analytic strategies with a nationally representative sample were conducted to identify behavior captured by this measure. Six core behavioral types or syndromes (phenotypic dimensions) were identified: Attention-Deficit Hyperactive, Solitary Aggressive-Provocative, Solitary Aggressive-Impulsive, OppositionalDefiant, Diffident, and Avoidant (McDermott, 1993). In addition, McDermott, Steinberg, \& Angelo (2005) identified three classroom situational dimensions where behavior problems occurred: Peer, Academic, and Teacher Problem Situations. The three underlying situational dimensions more parsimoniously described common demand characteristics shared among the ASCA's 29 classroom situations (Comrey, 1988; Gorsuch, 1983). While the behavioral dimensions assessed what type of behavioral problem, the situational dimensions or "situtypes" captured where in the classroom children's behavioral problems occurred in transaction with situational demands. (The word "situtype" was derived from the Latin meaning: type of situation or circumstance). McDermott, Steinberg, \& Angelo (2005) demonstrated both the unique and combined contribution of behavioral and situational dimensions to academic and social outcomes in elementary school.

Recently, this approach has been developed to study behavioral adjustment within early childhood educational settings for low-income, preschool children. The Adjustment Scales for Preschool Intervention (ASPI; Lutz, Fantuzzo, \& McDermott, 2002) was developed in partnership with early childhood professionals in a large urban, Head Start program. Like 
McDermott's research, this approach involved carefully identifying a comprehensive set of 22 developmentally appropriate preschool classroom situations. Early childhood professionals also helped to script the wording of the items so that both adaptive and maladaptive behaviors associated with these situations were described in the language of preschool teachers rather than in the psychiatric terms. This step was taken due to empirical studies that question the validity of teacher report of Head Start children's emotional and behavioral problems using psychiatric symptom checklists [e.g., many educators underreport the incidence and are reluctant to use measures that might stigmatize or label children and that are not associated with classroom-based services (Fantuzzo, Stoltzfus, Noone, Buchanan, Balraj, Turner, \& Mosca, 1999; Lutz, Fantuzzo, \& McDermott, 2002; Mallory \& Kearns, 1988).

To date, five behavioral dimensions of the ASPI have been established and their contribution alone documented to preschool outcomes: Aggressive, Oppositional, Hyperactive/Inattentive, Withdrawn/Low Energy, and Socially Reticent types of behavior problems (Lutz, Fantuzzo, \& McDermott, 2002). Research has shown that these behavioral dimensions relate to peer social competency, psychological adjustment, temperament, and emotion regulation (Bulotsky-Shearer \& Fantuzzo, 2004; Lutz et al., 2002). As well, the dimensions predicted classroom learning competency, receptive and expressive vocabulary, and peer social competency at the end of the preschool year (Fantuzzo, Bulotsky, McDermott, Mosca, \& Lutz, 2003).

This prior research documents the influence of types of behavioral problems within the preschool classroom. However, it does not examine how multiple contexts within the classroom (and their shared demand characteristics) differentially influence children's developmental outcomes. Informed by a developmental-ecological model, research is needed using a rigorous, 
multivariate approach to advance our understanding of the unique and combined influence of both types of behavior problems (child-level) and types of classroom problem situations (classroom contextual influences) on child social and academic outcomes. The purpose of the present study was to explore across the school year the influence of both types of classroom behavior problems on a comprehensive set of preschool readiness outcomes for low-income urban-residing, preschool children. In order to accomplish this objective, two empirical studies were conducted. The first study was designed to identify situational dimensions of problem behavior in Head Start by studying children's behavior problems across 22 routine classroom situations. The second study employed both the classroom situational dimensions empirically derived from the first study and previously established behavioral dimensions to examine the unique and combined influence on a multidimensional set of social and learning outcomes.

Study I: Identification of Classroom Situational Dimensions

The focus of the first study was to identify dimensions of classroom situations where problem behavior occurred in classrooms serving urban, low-income preschool children. To accomplish this goal, the latent structure of the ASPI's 22 routine classroom situations was investigated employing multivariate exploratory factor analytic strategies. This first step was needed to accomplish the larger study purpose of investigating the relationship between classroom situational dimensions and readiness outcomes. Based on prior research conducted by McDermott (2005), it was hypothesized that reliable and unique underlying dimensions would capture distinct types of common, routine classroom situational demands associated with preschool behavior problems.

Method

\section{Participants}


An entire population of Head Start children from a large urban school district in the northeast participated in this study. Of the 3,799 children, sex was split evenly, with females comprising $51 \%$ of the sample. Children ranged in age from 36 to 69 months $(M=51.5$ months, $S D=6.6)$ and were predominantly African American (73.5\%). Sixteen percent of the children were Latino, 7\% Caucasian, and 3.5\% Asian or other. The participants were predominantly lowincome, with annual income for 93\% of the program's families below $\$ 15,000$.

Children were enrolled in 233 classrooms geographically dispersed across the city. All teachers in the Head Start program participated and completed assessments on their children. Program demographic information indicated that all teachers were credentialed in early childhood education and had at least a bachelor's degree. The majority (61\%) had experience teaching in Head Start for at least five years and 35\% had more than ten years experience in Head Start. Teachers were predominantly Caucasian (62\%) with 29\% African-American, 3\% Latino, $1 \%$ Asian and 5\% other.

Measures

Emotional and behavioral adjustment. The Adjustment Scales for Preschool Intervention (ASPI; Lutz et al., 2002) was used to assess emotional and behavioral problems across routine preschool classroom situations. It was collected as part of the Head Start program's routine emotional/behavioral assessment of all children within the first 45 days of enrollment. The ASPI is a multidimensional instrument based on teacher observations of adaptive and maladaptive behavior across these classroom situations (Lutz et al., 2002). The scale's 144 behavioral items (122 items reflect problem behaviors, 22 reflect positive behaviors) are framed by 22 classroom situations and 2 categories of non-situationally specific behavior problems (e.g., unusual habits or outbursts) (see Appendix A1 for list of situations). The situations include interactions with the 
teacher, relationships with peers, involvement in structured and unstructured classroom activities, and games and play. To view examples of the item response format for situations, see Appendix A2 or Lutz et al. (2002).

The ASPI was standardized on a sample of urban Head Start children and validated for use with this population. Construct validity studies of ASPI with urban, low-income preschool populations have revealed five reliable behavioral (phenotypic) dimensions: Aggressive, Oppositional, Inattentive/Hyperactive, Withdrawn/Low Energy and Socially Reticent. Each of the five dimensions demonstrated adequate internal consistency, with Cronbach alpha coefficients of $.92, .78, .79, .85$ and .79 respectively (Lutz et al., 2002). The five dimensions were found to be replicable and generalizable to important subgroups of the standardization sample (i.e., younger and older children, boys and girls). Convergent and divergent validity of the five ASPI dimensions has been established with constructs of interactive peer play, behavior problems, temperament, emotion regulation, and direct observations of classroom behavior problems (Bulotsky-Shearer \& Fantuzzo, 2004). Predictive validity of the five ASPI dimensions has also been established with end-of-the-year preschool competencies including interactive peer play, classroom learning competencies, and receptive language skills (Fantuzzo et al., 2003).

\section{Procedures}

Archival data collection. This study was part of a larger collaborative university research partnership with an urban public school district Head Start program. Before data were obtained, a confidentiality agreement was signed to ensure the confidentiality of all identifying information. Archival data were prepared in cooperation with the School District's Office of Research and Evaluation and the Head Start program. This data set included, (a) demographic information routinely collected by the program on Head Start children, families and staff and (b) ASPI data 
collected at the beginning of the school year. The ASPI was collected by the program as part of a federal Head Start assessment requirement (Performance Standard, 1304.20; USDHHS, 1997). The ASPI was completed by teachers trained in its use and supervised by program staff.

\section{Data Analysis}

Latent structure. To examine the latent structure of the 22 ASPI situations, a series of exploratory latent structure analyses was conducted using squared multiple correlations as initial communality estimates (Snook \& Gorsuch, 1989). Before subjecting situations to factor analytic procedures, the prevalence of the 144 behaviors was examined in the sample of Head Start children to identify problematic behavioral items. This was a conservative psychometric step, because many of the items were scripted in partnership with teachers, based on what they considered "adaptive" or "maladaptive" behavior in each situation. Items with less than 50\% prevalence (occurring in less than $50 \%$ of the sample) were considered rare and possibly problematic behaviors. Items with greater than $50 \%$ prevalence (occurring in the majority of the sample) were considered more normative behaviors. These "adaptive" behavioral items were excluded from the next step in the analyses since the intended purpose of the ASPI was to measure emotional and behavioral difficulties ${ }^{1}$ (Lutz et al., 2002; McDermott \& Schaefer, 1996). The problem items endorsed in each situation were summed to create raw scores. These were scaled using area conversion and subjected to factor analytic procedures ${ }^{2}$ (Allen \& Yen, 1979; Thorndike, 1982).

Retained factors were rotated using orthogonal (varimax, equamax) rotations. The final orthogonal solution was subjected to a series of oblique (promax) rotations at increasing levels of power. The most parsimonious factor solution was evaluated based upon multiple criteria that: (a) satisfied the constraints of tests for the number of factors [e.g., Cattell's scree test (Cattell, 
1966), minimum-average partialing (Velicer, 1976), and parallel analysis (Buja \& Eyuboglu, 1992; Horn, 1965)]; (b) retained at least four items per factor with salient loadings, where loadings $\geq .40$ are considered salient (Gorsuch, 1983); (c) yielded reasonable internal consistency for each factor, with alpha coefficients $\geq .70$; (d) held simple structure (mutually exclusive assignment of items to factors with the maximum number of items retained); (e) yielded the highest hyperplane count (Yates, 1987); and (f) comported with the empirical psychological literature.

Three additional steps were taken to further verify the integrity of the proposed solution. First, specificity values were calculated to determine the reliable and unique variance associated with each situational dimension by subtracting each factor's communality (proportion of common variance within each scale) from its alpha coefficient (Gorsuch, 1983). Second, crossvalidation analyses were conducted to ensure the final solution's structural invariance and generalizability to important demographic subgroups within the sample, such as older and younger children, boys and girls, and different ethnic groups, respectively ${ }^{3}$. Oblique, multiplegroup, principal-components cluster analysis was conducted as a confirmatory procedure to verify further the final solution (Anderberg, 1973; Harman, 1976).

Finally, the structural model for the final exploratory solution was submitted to confirmatory factor analysis (CFA) using EQS-6 (Bentler \& Wu, 2002). Based upon maximum likelihood estimation, EQS-6 estimated several indices to evaluate the goodness-of-fit between the specified model and the data. Consistent with recommended practice, two indices were applied: the Comparative Fit Index (CFI) and Root-Mean-Square Error of Approximation (RMSEA) (see Bentler and Wu, 2002, Byrne, 1994, and Fabrigar, Wegener, MacCallum, and Strahan, 1999, on the application of CFA fit indices following exploratory factoring). Due to the 
extreme non-normal distribution of the data (positively skewed and highly leptokurtotic because of the nature of psychopathology items), robust fit indices were applied per Bentler and $\mathrm{Wu}$ (2002).

Age and sex differences. Significant age and sex differences across ASPI situational dimensions were investigated using repeated measures analysis of variance. A three-way analysis of variance was conducted where the first factor represented age (3-, 4-, or 5-year-old) and the second factor, sex. The third factor was held as a repeated measure representing ASPI situational dimensions. The purpose of this analysis was to examine the interaction effects of age group or sex with the repeated measure (ASPI situational dimension). Hedge's g as a measure of effect size was calculated for each significant effect (Cooper \& Hedges, 1994).

Statistical power. For exploratory factor analysis of the 22 ASPI situations, the sample size of 3,799 children was more than sufficient to detect latent structures, based on Gorsuch's (1983) recommendation of a minimum of 5-10 subjects per item for item-level factor analytic procedures. In addition, sample size was adequate to detect significant effects for a three-way repeated measures ANOVA [where a minimal total sample size of 216 was required to detect medium effects (with power set at .80 and alpha set at .05 significance level (Cohen, 1992)]. Results

\section{Classroom Situational Dimensions}

The correlation matrix of the 22 ASPI situations was evaluated using Bartlett's $\chi^{2}$ criteria (Geweke \& Singletone, 1980), rejecting the likelihood of an identity matrix $(p<.0001)$, and permitting investigation into latent structure. The 22 situations were subjected to a series of common factor analyses for two- to six-factor models (Snook \& Gorsuch, 1989). The threefactor, promax solution $(k=4$, with an equamax structure matrix serving as the initial orthogonal 
structure), produced the most useful and parsimonious solution that satisfied the six central criteria for retention, including high internal consistency across each factor $(.84, .81$, and .75 respectively) and the highest hyperplane count (34.85\%). The final structure was determined by examining the 19 items that loaded saliently on each of the factors. Table 1 displays the ASPI situations comprising the three dimensions, with their equamax and promax structure loadings.

The first dimension, Problems in Structured Learning, was comprised of seven structured or organized classroom situations associated with problematic behavior [involvement in class activities, taking part in games with others, maintaining companions/friends, paying attention in class, sitting during teacher-directed activities, free play/individual choice, and working with hands (Art)]. The second dimension, Problems in Peer Interaction, was comprised of six peer situations associated with problematic behavior in the classroom (getting along with agemates, behaving in classroom, respect for others' belongings, reaction to correction, telling the truth, and standing in line). The third dimension, Problems in Teacher Interaction, contained six classroom situations involving teachers where behavior problems occurred (talking to teacher, general manner with teacher, answering teacher questions, greeting teacher, seeking teacher help, and helping teacher with jobs).

To further verify the integrity of the promax, three-factor solution, final communality estimates were used to determine the proportion of specific variance associated with each situational dimension. While, intercorrelations among the retained unit-weighted scores for the three dimensions were moderately correlated (ranging from .43 to .62), the proportion of specific variance exceeded error variance for each dimension, providing evidence for the unique and reliable interpretation of each dimension. Studies of invariance and generalizability provided further evidence of the integrity of the final solution, with each of the three situational 
dimensions remaining invariant across random replications and important demographic subgroups as demonstrated by high Wrigley-Neuhaus coefficients of congruence (see Table 2). Internal consistencies for each of the dimensions were also high across the groups as indicated by Cronbach's alpha coefficient (see Table 3).

Both oblique, multiple-group, principal components cluster analysis confirmed the final structure as well as confirmatory factor analysis using EQS-6. Table 1 displays the situational item cluster loadings for the cluster analytic confirmatory procedure and the adjusted correlations between situational dimensions and items. The plausibility of the three-factor model was supported by CFA using EQS-6 (Bentler $\&$ Wu, 2002) with RMSEA $=.059$ and Bentler's CFI $=$ .880. Although the CFI did not reach criteria [greater than .90 cut-off according to Hu and Bentler (1999)], the RMSEA was adequate, providing converging evidence of an adequate structural fit for the three-factor model. According to Hu and Bentler (1999), a RMSEA close to .06 provides evidence that there is a relatively good fit between the hypothesized model and the observed data.

Age and Sex Differences

A 3 (age) x 2 (sex) x 3 (ASPI situational dimension) Repeated Measures ANOVA yielded two significant interactions between the repeated measure: age x ASPI situational dimension, $F(4,7032)=20.54, p<.0001$ and sex $\mathrm{x}$ ASPI situational dimensions, $F(2,7032)=$ $6.89, p<.01$. The interaction between age $\mathrm{x}$ sex $\mathrm{x}$ ASPI situational dimensions was not significant. Table 4 lists descriptive statistics on ASPI dimensions across age and sex. Post-hoc analyses (Tukey's HSD) revealed: (a) the youngest group of children (3-year-olds) demonstrated higher levels of problems $(p<.01)$, across all three classroom situational dimensions than did older children (4- and 5-year-olds); (b) 4-year-old children demonstrated significantly higher 
levels of problems than 5-year-olds $(p<.01)$, in Structured Learning situations and Teacher Interaction, and (c) boys demonstrated significantly higher problems $(p<.01)$, across all three situational dimensions. Effect sizes for all significant effects ranged from small to moderate as calculated by Hedge's g (Cooper \& Hedges, 1994) ${ }^{4}$.

\section{$\underline{\text { Study I: Discussion }}$}

This first study identified three distinct situational dimensions associated with preschool emotional and behavioral problems in classrooms serving urban, low-income children. Confirming initial hypotheses, exploratory factor analysis of 22 routine classroom situations revealed three reliable and unique situational dimensions: Problems in Structured Learning, Problems in Peer Interaction, and Problems in Teacher Interaction. Each dimension was comprised of classroom situations that shared common variance (e.g., similar classroom demand characteristics). The structural model was confirmed via confirmatory factor analysis.

The findings are supported by a recent study by McDermott et al. (2005) conducted with school-aged children where three comparable dimensions were derived: Peer, Academic, and Teacher Problems. While overall, preschool dimensions comport with those derived for schoolaged children, they are qualitatively distinct, reflecting experiences that are unique to early childhood classrooms. First, the situations reflect developmentally appropriate preschool content. Second, the situational dimension, Problems in Structured Learning, incorporates a number of social situations (e.g., taking part in games with others) that were not included in the comparable school-aged dimension, Academic Problems.

This reflects a difference between preschool and school-aged classroom demands. While educational approaches for older children rely more heavily on teacher-directed instruction, in preschool, cooperative peer activities are an essential part of the curriculum and are highly 
integrated within learning experiences for children (Bredekamp \& Rosengrant, 1992).

Recommendations for best practice in early childhood education are guided by the principles of

Piaget and Vygotsky that conceptualize development from a constructivist, interactive

perspective (Cole, John-Steiner, Scribner, \& Souberman, 1978; Ginsburg \& Opper, 1988). While

preschool teachers take an active role in mediating children's learning and play, instruction is

less teacher-directed than in formal schooling for older children. Play, child-directed learning

and free exploration should be central activities [National Association for the Education of

Young Children (NAEYC), 1997].

$\underline{\text { Findings revealed age and gender differences across all three classroom situational }}$

demands. A clear developmental sequence was found with the youngest age group (3-year-olds)

evidencing the greatest difficulties across all situations compared to 4- and 5-year-olds. Four-

year-olds lagged behind 5-year-olds in their adjustment to classroom learning and teacher-

mediated instructional situations. Boys evidenced greater adjustment difficulties across all

situations compared to girls. Both age and gender findings have been documented in the early

childhood literature for types of behavior problems and comport with recent Head Start studies

suggesting that (a) younger children demonstrate less emotional regulation and greater

withdrawn and inattentive classroom behavior problems than older children; and (b) boys

demonstrate higher levels of classroom behavior problems, particularly externalizing and

disruptive problems than girls (Coolahan et al., 2000; Fantuzzo, Grim, Mordell, McDermott,

Miller, \& Coolahan, 2001; Lutz, et al., 2002; Mendez, McDermott, \& Fantuzzo, 2002).

Study II: Contribution of Situational Dimensions to Preschool Outcomes

The purpose of this study was to investigate the unique relationship between the three classroom situational dimensions empirically derived in Study I and a set of multidimensional, 
school readiness outcomes for low-income, urban preschool children. Multivariate hierarchical setwise regression models were created to assess the unique contribution of problems in routine structured learning, peer interaction and teacher interaction classroom situations to social and learning outcomes, after controlling for the influence of child demographic variables and types of behavioral problems (aggressive, inattentive, oppositional, withdrawn-low energy, socially reticent behaviors). The combined contribution of both situational and behavioral dimensions was also examined, to explore whether including both the type of behavior problem as well as the situation where the problem occurred would explain greater variance in child outcomes. Based on prior research by McDermott (2005), it was hypothesized that situational dimensions would contribute unique variance to the prediction of social and learning outcomes and that the combined contribution of both situational and behavioral influences would be greater than either set alone.

Method

\section{Participants}

Data were obtained for a second cohort of children from a different year who were enrolled in the same urban, Head Start program as in Study I. This data set contained fall emotional and behavioral assessments (ASPI) as well as spring measures of peer social (PIPPST) and classroom learning competence (COR). Participants in this sample included 747 children who were representative of the entire program. Sex was split evenly with $48 \%$ male, and $52 \%$ female. They ranged in age from 36 to 73 months $(M=52.8, S D=7$ months $)$ and were $71 \%$ African American, 14\% Caucasian, 9\% Latino, 6\% Asian or other. These children were predominantly low-income, with annual income of $94 \%$ of families below $\$ 12,000$. 
Children were enrolled in 46 Head Start classrooms geographically dispersed throughout the city. The teachers in these classrooms volunteered to participate in this study and were recruited by the program's six Educational Coordinators, representing the program's six geographic clusters. The participation rate was $97 \%$. Demographic information for this sample

population sample for Study I). All teachers were credentialed in early childhood education and had at least a bachelor's degree. Thirty-five percent of the teachers had taught less than 10 years, $27 \%$ between 10 and 20 years, and $38 \%$ over 20 years experience. Teachers were predominantly Caucasian (66\%), with 31\% African-American.

\section{Outcome Measures}

Peer social competence. The teacher version of the Penn Interactive Peer Play Scale (PIPPS-T; Fantuzzo, Coolahan, Mendez, McDermott, \& Sutton-Smith, 1998) was used to assess children's interactive peer play competencies within the classroom context at the end of the Head Start year. The PIPPS-T is a 32-item rating scale used to measure common play behaviors that facilitate or interfere with prosocial peer interactions in the classroom. The PIPPS-T was developed in collaboration with Head Start parents and teachers specifically for use with low income, urban Head Start children. Reliability and validity studies of the PIPPS-T (Fantuzzo, et al., 1998) have revealed three dimensions: Play Interaction, Play Disruption and Play Disconnection. Internal consistency for each of the three dimensions is high (Cronbach alpha $=$ $.92, .91$ and .89 respectively). Convergent and divergent validity has been established using direct observations of play, peer sociometrics, and multivariate measures of learning behaviors, temperament, emotion regulation, psychological adjustment, and social skills (Coolahan, Fantuzzo, Mendez, \& McDermott, 2000; Fantuzzo et al., 1998; Mendez, McDermott, \& Fantuzzo, 2002). 
Classroom learning competence. The Child Observation Record (COR; High Scope Educational Research Association, 1992) is a 30-item observationally-based evaluation instrument designed for use with children ages $2 \frac{1}{2}$ to 6 years in early childhood settings. It measures several important domains of preschool development including emergent literacy, numeracy, social and motor competencies (Schweinhart, McNair, Barnes, \& Larner, 1993). Exploratory factor analysis of the COR with urban, low-income preschool children yielded three factors: Cognitive Skills, Social Engagement, and Coordinated Movement (Fantuzzo, Hightower, Grim, \& Montes, 2002). These dimensions demonstrated high internal consistency for urban Head Start children (i.e., Cronbach alpha $=.95, .93$ and .86 respectively). Convergent and divergent validity has been established with standardized assessments of peer play, receptive vocabulary, and psychological adjustment (Fantuzzo et al., 2003; Fantuzzo et al., 2002).

\section{Procedures}

Archival data collection. Data were collected in cooperation with the School District's Office of Research and Evaluation and the Head Start program in the same manner as collected in Study I. This data set included, (a) demographic information routinely collected by the program on Head Start children, families and staff, and (b) ASPI data collected in the fall, and (c) measures of peer social competence (PIPPS-T) and classroom learning competence (COR) collected in the late spring of that school year. In the spring, teachers completed the PIPPS-T for all children and completed the COR for 10 children in their classroom (five boys and five girls who were randomly selected to participate). The ASPI, PIPPS-T and COR were completed by teachers trained in the use of both instruments and supervised by program staff. Data Analysis 
Unique contribution of classroom situational problems to preschool outcomes. A series of multivariate hierarchical setwise multiple regression analyses were used to examine the unique contribution of ASPI situational dimensions to peer social (PIPPS-T) and classroom learning competencies (COR) at the end of the year accounting for demographic variables. Models were constructed for each set of competency dimensions (i.e., the three dimensions of PIPPS-T or COR). Child demographic variables (age, sex, and ethnicity) were applied as control variables to account for variation in criterion dimensions, by entering them first as a set. Next, ASPI behavioral dimensions (Aggressive, Oppositional, Hyperactive/Inattentive, Withdrawn/Low Energy, and Socially Reticent behavior problems) were entered into the model as a second set. Then, the situational dimensions (Structured Learning, Peer Interactions, and Teacher Interactions) were entered as a final independent set to assess their unique contribution to competency outcomes controlling for the influence of child demographic variables and behavioral dimensions. In these models, the presence of interaction effects between ASPI situational and behavioral dimensions was also investigated. This step incorporated sets of one or more of 15 multiplicative two-way interactions between the three situational and five behavioral dimensions in the model as a separate set. ${ }^{5}$

Combined contribution of situational and behavioral problems to preschool outcomes. Hierarchical setwise multiple regression was used in the same manner as above, however, both ASPI situational and behavioral dimensions were entered together as a final set to assess their combined contribution to the competency outcomes. The multivariate statistic, Wilks' Lambda (A), was examined before inspecting the overall significance of each model and the significance of the incremental value of each set entered (partial $R^{2}$ ). 
Statistical power. Sample size was adequate to detect significant effects for a hierarchical setwise multiple regression analysis. A minimal total sample size of 139 was required to detect medium effects [with power set at .80 and alpha set at .05 significance level (Cohen, 1992)].

Results

\section{Unique Contribution of Classroom Situational Problems}

Peer social competency. The overall Wilks' Lambda $(\Lambda)$ was significant (Wilks' $\Lambda=.30$, $F[51,2046.1]=19.81, p<.0001)$, permitting inspection of the three dependent models for the PIPPS-T dimensions: Play Disconnection, Play Disruption, and Play Interaction. All three [17, $706]=23.46, p<.0001$, respectively). Table 5 displays that the ASPI situational dimensions (Structured Learning, Peer Interaction, and Teacher Interaction) as a set accounted for a unique amount of variance in all three peer social competency dimensions as indicated by the partial $R^{2}$. The situational dimensions (e.g., where difficulties in the classroom occurred) added the greatest amount of unique variance in predicting disconnected play.

Table 6 displays the standardized regression coefficients for each of the ASPI situational and behavioral dimensions, and the significant interaction effects included in the model. The coefficients illustrated several patterns, reflecting the relative contribution of both situational and behavioral dimensions to peer social competency. (Note that unstandardized regression weights with standard errors for this model are displayed in Appendix B1). Looking more closely at the prediction of disconnected play, four dimensions predicted greater disconnected play outcomes: two situational dimensions (early problems in structured learning and peer interactions) and two behavioral (oppositional and socially reticent behaviors). Disruptive play was predicted by early oppositional behavior and problems in peer interaction while higher interactive play competency 
was associated with one behavioral dimension (lower oppositional behavior) and two situational (lower problems in structured learning and teacher interaction).

Three multiplicative interactions between situational and behavioral dimensions significantly improved the prediction of PIPPS-T dependent models. These included interactions between: (a) Problems in Teacher Interaction and Socially Reticent dimensions in the prediction of disconnected play; (b) Problems in Peer Interaction and Oppositional behavior in the prediction of disruptive play; (c) and Problems in Teacher Interaction and Oppositional behavior in the prediction of interactive peer play.

Interaction effects suggested that the presence of types of behavioral problems moderated the influence of classroom situational problems in the prediction of social competency outcomes (Cohen, Cohen, West, Aiken, 2003; Frazier, Tix, \& Barron, K. E., 2004). For example, the influence of problems in teacher interaction on disconnected play was moderated by the presence of socially reticent behavior. For children who demonstrated early problems in teacher interaction, disconnected peer play outcomes were intensified in the presence of increasing levels of early socially reticent behavior. For children exhibiting early problems in peer interaction, increasing levels of oppositional behavior predicted even greater disruptive play outcomes. Likewise, for children demonstrating early problems in teacher interaction, increasing levels of early oppositional behavior predicted lower interactive peer play at the end of the year.

Classroom learning competency. Table 7 indicates the amount of variation in dimensions of classroom learning competency (COR) explained by the set of ASPI situational dimensions after applying the five ASPI behavioral dimensions and child demographic variables as covariates. The overall Wilks' Lambda $(\Lambda)$ was significant (Wilks' $\Lambda=.46, F[51,1364.3]=$ 8.07, $p<.0001$ ), permitting inspection of the three COR dependent models for Cognitive Skills, 
Social Engagement, and Coordinated Movement. All three models were significant $(F[17,477]$

$=17.26, p<.0001, F[17,477]=16.99, p<.0001$, and $F[17,477]=14.14, p<.0001$, respectively). Situational dimensions contributed relatively greater variance to cognitive skills and movement and coordination than behavioral dimensions, indicating that for children early in the school year, problems in classroom situations as a set were a relatively strong influence on these two classroom learning outcomes.

Table 8 displays the pattern of standardized beta coefficients for the situational and behavioral dimensions and the significant interaction effects included in the model. The standardized coefficients reflect the relative contribution of both types of ASPI dimensions to COR classroom learning competencies. (Note that unstandardized regression weights with standard errors for this model are displayed in Appendix B2). Two multiplicative interactions between situational and behavioral dimensions significantly improved the prediction of COR dependent models: interactions between Problems in Structured Learning and Socially Reticent behavior and Problems in Peer Interaction and Inattentive/Hyperactive behavior.

The significant interaction effects suggested that the influence of problems in structured learning on cognitive and social engagement outcomes was moderated by socially reticent behavior. In other words, cognitive and social engagement performance (on the COR) was sharply diminished when children who demonstrated early problems in structured learning situations also demonstrated increasing levels of socially reticent behavior. In addition, the influence of problems in peer interaction on social engagement outcomes was moderated by the degree of inattentive/hyperactive behavioral problems. Children with early problems in peer interaction evidenced much lower social engagement outcomes when they also demonstrated higher levels of inattentive/hyperactive behavior early in the year. 


\section{Combined Contribution of Situational and Behavioral Problems}

Peer social competency. Table 9 displays the amount of variation in dimensions of the PIPPS-T explained by the combined set of situational and behavioral dimensions, covaried for child demographic and all other situational and behavioral variables. Situational and behavioral dimensions as a combined set together accounted for a significant amount of variance in Play Disconnection $(F=28.90, p<.0001)$, in Play Disruption $(F=61.08, p<.0001)$, and in Play Interaction $(F=28.06, p<.0001)$ as indicated by the partial $R^{2}$. This amount was greater than

Classroom learning competency. Table 10 indicates the amount of variation in dimensions of the COR explained by the combined set of situational and behavioral dimensions, covaried for child demographic and all other ASPI situational and behavioral variables. The combined set together accounted for a significant amount of variance in all three COR outcomes: Movement $(F=17.89, p<.0001)$ as indicated by the partial $R^{2}$. This amount was greater than either set alone.

\section{Study II: Discussion}

$\underline{\text { Study II advanced our understanding of the importance of considering classroom }}$ $\underline{\text { situational adjustment influences on social and classroom learning outcomes for low-income }}$ urban preschool children. The study investigated the unique relationship between the three classroom situational dimensions empirically derived in Study I and a set of multidimensional school readiness outcomes. Behavior problems in each of the three situational dimensions were associated differentially with lower social or learning outcomes (above and beyond the contribution of already established behavioral dimensions and child covariates). Of note, is the important contribution of structured learning situations to both children's peer social competency and learning outcomes. In this study, children evidenced problematic adjustment across multiple 
learning situations (for example, attending or sitting during teacher-directed activities, engaging in circle time, or sitting and working with their hands to create artwork). Early problems in these structured learning situations predicted both greater disconnection from peers (on the PIPPS-T) and lower classroom learning competencies (on the COR) at the end of the year. Early childhood research underscores the critical importance of children's engagement in everyday preschool classroom learning situations to their school adjustment and success. This research indicates that children with difficulties engaging in the rich learning opportunities afforded within early preschool learning situations are more likely to demonstrate both lower social and academic readiness outcomes (Huffman, Mehlinger, \& Kerivan, 2000; Shonkoff \& Phillips, 2000). This study also adds to the empirical literature emphasizing the importance of negotiating the interpersonal demands of social classroom situations for preschool children. In this study, children who evidenced early problems in peer or teacher interactions demonstrated greater peer social difficulties at the end of the year (greater disconnected and disruptive play). Research provides support for this finding, linking emotional adjustment to social competence within the preschool classroom (Denham, 1998; Denham et al., 2003; Fabes et al., 1999). These studies $\underline{\text { suggest that children exhibiting emotional and behavioral problems within social classroom }}$ $\underline{\text { situations are likely to experience peer difficulties as well (Denham, McKinley, Couchoud, \& }}$ Holt, 1990; Eisenberg \& Fabes, 1992; Olson, 1992). Other research indicates that preschool children evidencing problematic behavior with teachers are also likely to experience difficulties in peer interactions (Birch \& Ladd, 1997; Coplan \& Prakash, 2003; Kontos \& Wilcox-Herzog, 1997). Research conducted recently in Head Start provides further evidence that children with $\underline{\text { socially disruptive or disconnected behavior problems in the classroom also display social }}$ difficulties (Fantuzzo, Sekino, \& Cohen, 2004; Lutz, et al., 2002; Olson, 1992). 
The present study advances the knowledge base by capturing a reliable and unique set of peer and teacher situations associated with problem behavior and relating them differentially to $\underline{\text { multiple dimensions of social outcomes for low-income, urban preschool children. Findings }}$ $\underline{\text { suggest that for children navigating multiple ecological risks to their social development, }}$ $\underline{\text { behavioral difficulties in classroom social situations early on can have detrimental effects on }}$ developmental trajectories. Identifying and understanding these early influences can inform $\underline{\text { strategic interventions to promote more successful behavioral adaptation in preschool, future }}$ $\underline{\text { social adjustment and academic success. }}$

$\underline{\text { In keeping with a developmental-ecological perspective, this study extends prior research }}$ by investigating the combined contribution of both situational (classroom microsystem) and behavioral (individual child-level ontogenetic) dimensions simultaneously. Findings underscore $\underline{\text { the importance of empirically examining multiple levels of ecological influences at the same }}$ $\underline{\text { time, in a transactional way (Bronfenbrenner and Morris, 1998). Previous studies have }}$ documented the independent influence of types of behavior problems alone on child outcomes (e.g., Coolahan et al., 2000; Fantuzzo, et al., 2001; Fantuzzo et al., 2003; Lutz et al., 2002). While behavioral dimensions provide information about the types of behavioral characteristics children exhibit in the classroom, situational dimensions capture unique information about the situations where behavioral problems occur. This study provides evidence that both sets of dimensions together provide more information than either set alone in predicting developmental outcomes for low-income, urban preschool children. These findings comport with McDermott et al. (2005) who obtained a more comprehensive understanding of achievement and social $\underline{\text { adjustment outcomes for school-aged children when a combination of both situational and }}$ behavioral dimensions was considered. This suggests that not only is it critical to understand the 
types of problem behavior children exhibit as children transition to preschool, but also it is critical to understand the multiple classroom learning situations that demand a host of developmental skill sets for children to successfully adapt and learn across the school year.

Further, results from this study suggest that behavioral dimensions moderated the influence of situational problems in the prediction of multiple social and classroom learning competencies. This finding advances the field because it affords a closer look at how the two types of information about child behavior work together to influence children's outcomes in a dynamic, transactional way. For example, in this study, the influence of problems in structured learning situations on children's learning outcomes was amplified for children exhibiting socially $\underline{\text { reticent problems. As children who struggling behaviorally in structured learning situations early }}$ in the year exhibited increasing levels of socially reticent behavior, their cognitive skills and $\underline{\text { social engagement outcomes diminished appreciably. Such children were at heightened risk for }}$ poor learning outcomes at the end of the year. As well, the negative influence of problems in peer interactions on children's social engagement was intensified when children exhibited inattentive/hyperactive problems. Understanding the nature of these interactions can guide intervention efforts, helping to target children who exhibit specific combinations of behavioral and situational difficulties known to relate differentially to important competency outcomes.

\section{Discussion}

Informed by a developmental-ecological model, the present research explored the dynamic, transactional relationships between children's behavior and the demands of routine classroom situations for low-income preschool children. This research involved a sequence of two studies - one identifying types of situations in which classroom behavior problems occur 
and the second investigating the unique relationship between early problems in these types of situations and end-of-the-year school readiness outcomes.

Findings underscore the importance of empirically examining multiple levels of ecological influences at the same time, in a dynamic, transactional way, particularly for vulnerable children exhibiting behavioral difficulties within the classroom context. Developmental research highlights a complex array of multiple child-level factors and aspects of the broader social context that over time influence children's behavioral adjustment and academic readiness (Bronfenbrenner and Morris, 1998). Children must use their internal $\underline{\text { resources and developmental competencies (cognitive, language, social, emotional and physical }}$ skills) to navigate central tasks (demands) of development as a function of their age and culture (Cicchetti \& Toth, 1997). This is a dynamic process which changes over time at multiple levels (McWayne, Fantuzzo \& McDermott, 2004). Empirical research such as this current study using a multidimensional and transactional approach captures these complex processes for young children and provides rich data to inform future intervention efforts.

\section{Directions for Future Research}

This is the first step in an investigation of multiple dimensions of routine, preschool classroom situations associated with problematic adjustment. This study contributes to the knowledge base by (a) empirically documenting three unique and reliable situational dimensions for an entire population of Head Start children early in the school year, and (b) relating these dimensions differentially to classroom social and learning outcomes. The findings also provide support for the developmental-ecological model by capturing the complex, dynamic process $\underline{\text { through which low-income children experience early behavioral problems across routine }}$ classroom situations and the influence of such problems over time. Specifically, findings provide 
evidence to suggest that it is critical to understand (a) the dynamic transaction between

ontogenetic capacities of the developing child and the cognitive and social demands of classroom $\underline{\text { situations, and (b) the influence of multiple risks in context on children's development and }}$ $\underline{\text { behavior over time (e.g., certain combinations of difficulties across ontogenetic and microsystem }}$ contexts can modify outcomes).

In this study, three situational dimensions were documented for a predominantly Englishspeaking African-American, urban Head Start population in the Northeast. Future research is needed to investigate the generalizability of these dimensions to other ethnic and linguistic groups of children across diverse geographic areas. This need is documented by research that shows interpretation of situational demands and appropriate behavior varies across cultural and linguistic communities (Garcia Coll, Akerman, \& Cicchetti, 2000; Garcia Coll \& Garrido, 2000; Ogbu, 1999).

This was also the first large scale, multi-method investigation of the relationship between situational dimensions of classroom behavioral adjustment and social and learning outcomes. The sole reliance on teacher report and observation of children's classroom behavior and learning is a potential limitation of this study. The limitation is mitigated by the fact that ASPI situational dimensions were assessed in the fall and outcome measures were assessed in the spring of the school year (i.e., at 2 different time periods). In addition, reliance on teacher report of classroom behavior should be considered within the context of the limited multi-source, assessment technology valid for diverse, low-income preschool children (Rogers, 1998; USDHHS, 2002). For this study, the measures called for ratings of children's behavior and learning across different classroom contexts (e.g., free play, circle time, structured learning activities) over a period of 4-6 weeks. For large-scale studies such as the present one, teachers 
are the most appropriate source for accurate observations of children's behaviors within the natural classroom context (McDermott, 1986). Nonetheless, future smaller scale studies could test the present findings by using independent observers and assessors to evaluate children's educational and social outcomes. Incorporating outcome measures from additional sources will enhance our understanding of the relationships under study, and provide additional validity for the ASPI situational dimensions (APA, 1999; Lidz, 2003; Nuttall, Romero, \& Kalesnik, 1999).

While this study examined classroom situational influences on behavioral adjustment and preschool outcomes across the school year, future studies can extend our understanding of these situational influences by incorporating information from additional relevant contexts and across additional time periods. From a developmental-ecological perspective, research that accounts for the variance attributable to multiple contextual factors over additional time periods will broaden our understanding of complex risk or protective influences on children's developmental trajectories (Boyce et al., 1998; Bronfenbrenner \& Morris, 1998; Cicchetti \& Toth, 1997). Attention to important variables such as neighborhood, family, classroom and teacher-level factors, particularly across important transitions for children (e.g., into kindergarten and elementary school) would inform our understanding of the developmental trajectories of vulnerable children exhibiting early adaptation difficulties.

Finally, future studies could extend the present study by examining profiles of behavioral and situational adjustment for low-income, preschool children. In the present study, the significant interaction effects in the setwise regression models provided important information about the combinations of behavioral and situational difficulties that influence preschool social and learning outcomes. However, a multivariate cluster analysis could provide a different looka person-centered or typological approach to understanding distinct profiles of groups of 
children. In this technique, multiple child characteristics (such as ASPI situational and behavioral adjustment as well as social and learning competencies) could be examined for distinct patterns of functioning among the Head Start children in the sample (Magnusson \& Bergmann, 1988). These profiles could yield information regarding patterns of strengths and needs that can inform strategic information for subgroups of children.

\section{Implications for Policy and Practice}

In this study, behavioral problems were captured in transaction with routine classroom demands for low-income, preschool children. It is responsive to a recent report by the Surgeon General calling for a developmentally and ecologically sensitive approach to identify emotional and behavioral needs for low-income, diverse preschool populations. The report prioritizes the need for: (1) creation of new methods that reduce stigma and avoid psychiatric labeling in childhood assessment and (2) expansion of the availability of new tools and methods that capitalize on "natural" resources for children within naturalistic contexts (USDHHS, 2001). This study is a crucial step toward building the knowledge base for understanding behavioral adjustment for diverse, low-income preschool populations. Rather than employing a method reflecting a traditional mental health model, the present study applied a developmentalecological approach that recognizes the multiple, dynamic influences on children's classroom adjustment over time (Bronfenbrenner \& Morris, 1998).

The derived situational dimensions provide a means to capture the dynamic, multidimensional transactional process through which behavioral difficulties arise for young children (Sroufe, 1997). The dimensions reflect the shared demand characteristics of preschool peer, teacher, and learning classroom situations associated with problematic adjustment. These dimensions identify where problematic behavior occurs in transaction with child capacities. This 
ecological approach shifts identification of "the problem" from the individual child to the broader classroom context (Henggeler, 1994). Further, children's behavior is recorded by teachers (natural contributors to children's development) within the natural context of common, routine classroom situations (Fantuzzo, McWayne, \& Bulotsky, 2003).

Applied in practice, situational dimensions can be used in concert with behavioral dimensions to identify a range of behavioral needs and to inform classroom-based intervention. Study findings suggest that when both sets of dimensions are used together, they inform a more comprehensive understanding of the trajectories of children exhibiting early behavioral needs. Data could be used to identify both situations where children may demonstrate adjustment difficulties (across learning, peer, or teacher situations) as well as what type(s) of potential behavioral characteristics (aggressive, inattentive, oppositional, withdrawn-low energy, or socially reticent) children evidence within the preschool classroom. These data can be used as a stepping stone by teachers and professional staff to determine how well the child's behavior matches environmental expectations, and identify behaviors, settings, and conditions that warrant intervention (Evans \& Evans, 1990). This approach would shift the intervention goal from fixing the child to a more developmental-ecological approach (making the system work) (Swartz \& Martin, 1997).

Reliable information about situations where problematic behavior occurs can be used also to inform program-wide interventions. Data collected programmatically could stimulate program-wide educator dialogue with regard to children's classroom mental health needs. Program-wide data on high frequency classroom situations that are most challenging can be shared with teachers and professional staff to promote discussion about teacher concerns and training needs. Classroom management and intervention strategies can be generated that target 
common situational challenges. Exemplary teachers can share techniques and brainstorm additional strategies with other teachers and staff. Utilizing the situational data professional staff can also serve as consultants to classroom teachers, providing additional training and support as needed. In addition, each classroom situational dimension can be examined to determine its specific cognitive, linguistic, social, or physical demand characteristics. In collaboration with teachers, a curriculum can be created that supports the development of developmental skill sets required for success across each routine classroom context. These next steps will require collaboration and partnerships with teachers, school personnel, parents, peers, and community members (Swartz \& Martin, 1997). 


\section{References}

Achenbach, T. M. (1991). Child Behavior Checklist. Burlington, VT: University of Vermont. Allen, M. J., \& Yen, W. M. (1979). Introduction to measurement theory. Monterey, CA: Brooks/Cole.

American Psychological Association. (1999). Standards for Educational and Psychological Testing. Washington, DC: author.

Anderberg, M. R. (1973). Cluster analysis for applications. New York: Academic Press.

Belsky, J., \& MacKinnon, C. (1994). Transition to school: Developmental trajectories and school experiences. Early Education \& Development. Special Issue: School readiness: Scientific perspectives, 5(2), 106-119.

Birch, S. H., \& Ladd, G. W. (1997). The teacher-child relationship and children's early school adjustment. Journal of School Psychology, 35(1), 61-79.

Barnett, W. S. (1998). Early care and education for children in poverty : promises, programs, and long-term results. Albany, NY: State University of New York Press.

Belsky, J. (1993). Etiology of child maltreatment: A developmental-ecological analysis. Psychological Bulletin, 114(3), 413-434.

Bentler, P. M., \& Wu, E. J. C. (2002). EQS-6 for Windows. Encino, CA: Multivariate Software. Boyce, W. T., Frank, E., Jensen, P. S., Kessler, R. C., Nelson, C. A., \& Steinberg, L. (1998). Social context in developmental psychopathology: Recommendations for future research from the MacArthur Network on Psychopathology and Development. Development \& Psychopathology, 10(2), 143-164. 
Bredekamp, S., \& Rosegrant, T. (1992). Reaching potentials: Appropriate curriculum and assessment for young children (Vol. 1). Washington, DC: National Association for the Education of Young Children.

Bronfenbrenner, U. (1979). The ecology of human development. Cambridge, MA: Harvard University Press.

Bronfenbrenner, U., \& Morris, P. A. (1998). The ecology of developmental processes. In W. Damon (Ed.), Handbook of child psychology: Theoretical Models of Human Development (5th ed., Vol. 1). New York: John Wiley \& Sons, Inc.

Buja, A., \& Eyuboglu, N. (1992). Remarks on parallel analysis. Multivariate Behavioral Research, 27(4), 509-540.

Bulotsky-Shearer, R. \& Fantuzzo, J. (2004). Adjustment Scales for Preschool Intervention: Extending validity and relevance across multiple perspectives. Psychology in the Schools $41(7), 725-736$

Byrne, B. M. (1994). Structural equation modeling with EQS and EQS/Windows: Basic concepts, applications, and programming. London: Sage Publications.

Campbell, S. B. (1995). Behavior problems in preschool children: A review of recent research. Journal of Child Psychology \& Psychiatry \& Allied Disciplines, 36(1), 113-149.

Carta, J. J., Sainato, D. M., \& Greenwood, C. R. (1988). Advances in the ecological assessment of classroom instructrion for young children with handicaps. In S. L. Odom \& M. B. Karnes (Eds.), Early intervention for infants \& children with handicaps: An empirical base (pp. 217-239). Baltimore, MD: Paul H. Brookes Publishing Co.

Cassidy, D. J., Hestenes, L. L., Hegde, A., Hestenes, S., \& Mims, S. (2005). Measurement of quality in preschool child care classrooms: An exploratory and confirmatory factor 
analysis of the early childhood environment rating scale-revised. Early Childhood Research Quarterly, 20, 345-360.

Cattell, R. B. (1966). The scree test for the number of factors. Multivariate Behavioral Research, $1(2), 245-276$.

Cicchetti, D., \& Sroufe, L. A. (2000). The past as prologue to the future: The times, they've been a-changin'. Development \& Psychopathology. Special Issue: Reflecting on the past and planning for the future of developmental psychopathology, 12(3), 255-264.

Cicchetti, D., \& Toth, S. L. (1997). Transactional ecological systems in developmental psychopathology. In S. S. Luthar, J. A. Burak, D. Cicchetti \& J. R. Weisz (Eds.), Developmental psychopathology: Perspectives on adjustment, risk, and disorder (pp. 317-348). Cambridge, England: Cambridge University Press.

Cohen, J. (1992). A power primer. Psychological Bulletin, 112(1), 155-159.

Cohen, J., Cohen, P., West, S., \& Aiken, L. S. (2003). Applied multiple regression/correlation analysis for the behavioral sciences. ( $3^{\text {rd }}$ ed.). Mahwah, NJ: Lawrence Erlbaum.

Cole, M., John-Steiner, V., Scribner, S., \& Souberman, E. (Eds.). (1978). Mind in society: The development of higher psychological processes. L. S. Vygotsky. Cambridge: Harvard University Press.

Comrey, A. L. (1988). Factor-analytic methods of scale development in personality and clinical psychology. Journal of Consulting \& Clinical Psychology, 56(5), 754-761.

Coolahan, K., Fantuzzo, J., Mendez, J., \& McDermott, P. (2000). Preschool peer interactions and readiness to learn: Relationships between classroom peer play and learning behaviors and conduct. Journal of Educational Psychology, 92(3), 458-465. 
Cooper, H. \& Hedges, L. (1994). (Eds.) Handbook of research synthesis. NY: Russell Sage Foundation.

Coplan, R. J., \& Prakash, K. (2003). Spending time with teacher: Characteristics of preschoolers who frequently elicit versus initiate interactions with teachers. Early Childhood Research Quarterly, 18(1), 143-158.

Denham, S. A. (1998). Emotional development in young children. New York: Guilford Press.

Denham, S. A., Blair, K. A., DeMulder, E., Levitas, J., Sawyer, K., Auerbach-Major, S., et al. (2003). Preschool emotional competence: Pathway to social competence. Child Development, 74(1), 238-256.

Denham, S. A., McKinley, M., Couchoud, E. A., \& Holt, R. (1990). Emotional and behavioral predictors of preschool peer ratings. Child Development, 61(4), 1145-1152.

Duncan, G. J., \& Brooks-Gunn, J. (1997). Consequences of growing up poor. New York: Russell Sage Foundation Press.

Eisenberg, N., \& Fabes, R. A. (1992). Emotion, regulation, and the development of social competence. In M. S. Clark (Ed.), Emotion and social behavior. Review of personality and social psychology (Vol. 14, pp. 119-150). Thousand Oaks, CA: Sage Publications, Inc.

Entwisle, D. R., \& Alexander, K. L. (1993). Entry into school: The beginning school transition and educational stratification in the United States. Annual Review of Sociology, 19, 401423.

Evans, W. H., \& Evans, S. S. (1990). Ecological assessment guidelines. Diagnostique, 16, 49-51. 
Fabes, R. A., Eisenberg, N., Jones, S., Smith, M., Guthrie, I., Poulin, R., et al. (1999).

Regulation, emotionality, and preschoolers' socially competent peer interactions. Child Development, 70(2), 432-442.

Fabrigar, L. R., Wegener, D. T., MacCallum, R. C., \& Strahan, E. J. (1999). Evaluating the use of exploratory factor analysis in psychological research. Psychological Methods, 4, 272299.

Fantuzzo, J. W., Bulotsky, R., McDermott, P., Mosca, S., \& Lutz, M. N. (2003). A multivariate analysis of emotional and behavioral adjustment and preschool educational outcomes. School Psychology Review, 32(2), 185-203.

Fantuzzo, J. W., Coolahan, K., Mendez, J., McDermott, P., \& Sutton-Smith, B. (1998). Contextually-relevant validation of peer play constructs with African American Head Start children: Penn Interactive Peer Play Scale. Early Childhood Research Quarterly, $13(3), 411-431$.

Fantuzzo, J. W., Grim, S., Mordell, M., McDermott, P., Miller, L., \& Coolahan, K. (2001). A multivariate analysis of the revised Conners' Teacher Rating Scale with low-income, urban preschool children. Journal of Abnormal Child Psychology, 29(2), 141-152.

Fantuzzo, J. W., Hightower, D., Grim, S., \& Montes, G. (2002). Generalization of the Child Observation Record: A validity study for diverse samples of urban, low-income preschool children. Early Childhood Research Quarterly, 17(1), 106-125.

Fantuzzo, J. W., \& Mohr, W. K. (2000). Pursuit of wellness in Head Start: Making beneficial connections for children and families. In D. Cicchetti \& J. Rappaport (Eds.), The promotion of wellness in children and adolescents (pp. 341-369). Washington, DC: Child Welfare League of America, Inc. 
Fantuzzo, J. W., McWayne, C., \& Bulotsky, R. (2003). Forging strategic partnerships to advance mental health science and practice for vulnerable children. School Psychology Review, $32(1), 17-37$.

Fantuzzo, J. W., Sekino, Y., \& Cohen, H. L. (2004). An Examination of the Contributions of Interactive Peer Play to Salient Classroom Competencies for Urban Head Start Children. Psychology in the Schools, 41(3), 323-336.

Fantuzzo, J. W., Stoltzfus, J., Noone, M., Buchanan, H., Balraj, V., Turner, C., \& Mosca, S. (1999). An empirical assessment of the special needs referral process in Head Start for children with emotional and behavioral problems. Early Childhood Research Quarterly, 14, 465-482.

Frazier, P. A., Tix, A. P., \& Barron, K. E. (2004). Testing Moderator and Mediator Effects in Counseling Psychology Research. Journal of Counseling Psychology, 51(1), 115-134.

Feil, E. G., Severson, H. H., \& Walker, H. M. (1995). Identification of critical factors in the assessment of preschool behavior problems. Education \& Treatment of Children. Special Issue: Severe behavior disorders of children and youth, 18(3), 261-271.

Friedman, S. L., \& Wachs, T. D. (Eds.). (1999). Measuring the environment across the life span: Emerging methods and concepts. Washington, DC: American Psychological Association.

Garbarino, J. (1995). Raising children in a socially toxic environment. San Francisco: JosseyBass.

Garcia Coll, C., Akerman, A., \& Cicchetti, D. (2000). Cultural influences on developmental processes and outcomes: Implications for the study of development and psychopathology. Development \& Psychopathology, 12, 333-356. 
Garcia Coll, C., \& Garrido, M. (2000). Minorities in the United States: Sociocultural context for mental health and developmental psychopathology. In A. Sameroff \& M. Lewis (Eds.), Handbook of developmental psychopathology (2nd ed., pp. 177-195). Dordrecht, Netherlands: Kluwer Academic Publishers.

Geweke, J. F., \& Singletone, K. J. (1980). Interpreting the likelihood ratio statistic in factor models when sample size is small. Journal of the American Statistical Association, 75, 133-137.

Ginsburg, H. P. \& Opper, S. (1988). Piaget's theory of intellectual development. Englewood Cliffs, NJ: Prentice-Hall.

Goldstein, S. (1995). Understanding and managing children's classroom behavior. New York: John Wiley \& Sons, Inc.

Gorsuch, R. L. (1983). Factor Analysis (2nd ed.). Hillsdale, NJ: Lawrence Erlbaum Associates.

Guadagnoli, E., \& Velicer, W. F. (1991). A comparison of pattern matching indices. Multivariate Behavioral Research, 26(2), 323-343.

Harman, H. H. (1976). Modern factor analysis (3rd ed.). Chicago, IL: University of Chicago Press.

Harms, T., Clifford, R., \& Cryer, D. (1998). Early childhood environment rating scale-revised. New York: Teachers College Press.

Henggeler, S. W. (1994). A consensus: Conclusions of the APA task force report on innovative models of mental health services for children, adolescents, and their families. Journal of Clinical Child Psychology. Special Issue: Task force report on innovative models of mental health services for children, adolescents, and their families, 23(Suppl), 3-6. 
High Scope Educational Research Association. (1992). Child Observation Record. Ypsilanti, MI: High/Scope Educational Research Foundation.

Horn, J. L. (1965). A rationale and test for the number of factors in factor analysis. Psychometrika, 30(2), 179-185.

Hu, L.T., \& Bentler, P. M. (1998). Fit indices in covariance structure modeling: Sensitivity to underparameterized model misspecification. Psychological Methods, 3, 424-453.

Huffman, L. C., Mehlinger, S. L., \& Kerivan, A. S. (2000). Off to a good start: Research on the risk factors for early school problems and selected federal policies affecting children's social and emotional development and their readiness for school. Chapel Hill: University of North Carolina, Frank Porter Graham Child Development Center.

Jensen, P. S., \& Hoagwood, K. (1997). The book of names: DSM-IV in context. Development \& Psychopathology, 9, 231-249.

Jensen, P. S., Koretz, D., Locke, B. Z., Schneider, S., Radke-Yarrow, M., Richters, J. E., et al. (1993). Child and adolescent psychopathology research: Problems and prospects for the 1990's. Journal of Abnormal Child Psychology, 21(5), 551-580.

Kontos, S., \& Wilcox-Herzog, A. (1997). Influences on children's competence in early childhood classrooms. Early Childhood Research Quarterly, 12, 245-262.

Lavigne, J. V., Gibbons, R. D., Christoffel, K. K., Arend, R., Rosenbaum, D., Binns, H., et al. (1996). Prevalence rates and correlates of psychiatric disorders among preschool children. Journal of the American Academy of Child \& Adolescent Psychiatry, 35(2), 204-214.

Lidz, C. S. (2003). Early childhood assessment. Hoboken, NJ: John Wiley \& Sons, Inc. 
Lutz, M. N., Fantuzzo, J., \& McDermott, P. (2002). Multidimensional assessment of emotional and behavioral adjustment problems of low-income preschool children: Development and initial validation. Early Childhood Research Quarterly, 17(3), 338-355.

Magnusson, D., \& Bergmann, L. R. (1988). Individual and variable-based approaches to longitudinal research on early risk factors. In M. Rutter (Ed.), Studies of psychosocial risk: The power of longitudinal data (pp. 45-61). New York, NY: Cambridge University Press.

Mallory, B. L., \& Kearns, G. M. (1998). Consequences of categorical labeling of preschool children. Topics in Early Childhood Special Education, 8, 39-50.

McDermott, P. A. (1993). National standardization of uniform multisituational measures of child and adolescent behavior pathology. Psychological Assessment, 5(4), 413-424.

McDermott, P. A. (1986). The observation and classification of exceptional child behavior. In R. T. Brown \& C.R. Reynolds (Eds.), Psychological perspectives on childhood exceptionality: A handbook (pp. 136-180). New York: Wiley-Interscience.

McDermott, P. A., Marston, N. C., \& Stott, D. H. (1993). National profiles in youth psychopathology: Manual of Adjustment Scales for Children and Adolescents. Philadelphia: Edumetric and Clinical Science.

McDermott, P. A., Steinberg, C. M., \& Angelo, L. E. (2005). Situational specificity makes the difference in assessment of youth behavior disorders. Psychology in the Schools, 42 (2), 121-136.

McEvoy, A. \& Welker, R. (2000). Antisocial behavior, academic failure, and school climate: A critical review. Journal of Emotional \& Behavioral Disorders, 8(3), 130-140. 
McEvoy, M. A. (1990). The organization of caregiving environments: Critical issues and suggestions for future research. Education \& Treatment of Children. Special Issue: Organizing caregiving environments for young children with handicaps, 13(4), 269-273.

McLoyd, V. C. (1998). Socioeconomic disadvantage and child development. American Psychologist, 53(2), 185-204.

Mendez, J. L., McDermott, P., \& Fantuzzo, J. (2002). Identifying and promoting social competence with African American preschool children: Developmental and contextual considerations. Psychology in the Schools, 39(1), 111-123.

NAEYC. (1997). Developmentally appropriate practice in early childhood programs serving children from birth through age 8. Retrieved April 6, 2004, from http://www.naeyc.org/resources/position_statements/psdap98.pdf

NICHD Early Child Care Research Network. (2000). The relation of child care to cognitive and language development. Child Development, 71, 960-980.

Nuttal, E. V., Romero, I., \& Kalesnik, J. (1999). Assessing and screening preschoolers: psychological and educational dimensions. Boston, MA: Allyn and Bacon.

Ogbu, J. U. (1999). Cultural context of children's development. In H. E. Fitzgerald, B. M. Lester \& B. Zuckerman (Eds.), Children of color: Research, health, and policy issues (pp. 7392). New York, NY: Garland Publishing, Inc.

Olson, S. L. (1992). Development of conduct problems and peer rejection in preschool children: A social systems analysis. Journal of Abnormal Child Psychology, 20(3), 327-350.

Peisner-Feinberg, E., Burchinal, M. R., Clifford, R. M., Culkin, M., Howes, C., Kagan, S. L., et al. (2001). The relation of preschool child-care quality to children's cognitive and social development trajectories through second grade. Child Development, 72, 1534-1553. 
Perlman, M., Zellman, G.L., \& Le, V. (2004). Examining the psychometric properties of the early childhood rating scale revised (ECERS-R). Early Childhood Research Quarterly, $19,398-412$.

Qi, C. H., \& Kaiser, A. P. (2003). Behavior problems of preschool children from low-income families: Review of the literature. Topics in Early Childhood Special Education, 23(4), 188-216.

Raver, C. C. (2002). Emotions matter: Making the case for the role of young children's emotional development for early school readiness. Retrieved November 1, 2003, from http://www.srcd.org/spr.html.

Raver, C. C., \& Knitzer, J. (2002). Ready to Enter: What research tells policymakers about strategies to promote social and emotional school readiness among three- and four-yearold children. New York: National Center for Children in Poverty, Mailman School of Public Health, Columbia University.

Rogers, M. R. (1998). Psychoeducational assessment of culturally and linguistically diverse children and youth. In H. B. Vance (Ed.), Psychological assessment of children: Best practices for school and clinical settings (2nd ed., pp. 355-384). New York: John Wiley \& Sons.

Sameroff, A. (1975). Transactional models in early social relations. Human Development, 18(12), 65-79.

Sameroff, A., \& Chandler, M. J. (1975). Reproductive risk and the continuum of caretaking casualty. In F. D. Horowitz (Ed.), Review of Child Development Research (Vol. 4, pp. 187-244). Chicago: University of Chicago Press. 
Sameroff, A., \& Fiese, B. H. (2000). Models of development and developmental risk. In C. H. J. Zeanah (Ed.), Handbook of infant mental health (2nd ed., pp. 3-19). New York: Guilford Press.

Schweinhart, L. J., McNair, S., Barnes, H., \& Larner, M. (1993). Observing young children in action to assess their development: The High/Scope Child Observation Record study. Educational \& Psychological Measurement, 53(2), 445-455.

Sherrod, L. (1999). A commentary on "Head Start and mental health: An argument for early screening and intervention" by Edward G. Feil. National Head Start Association Dialog, 2, 412-415.

Shonkoff, J. P., \& Phillips, D. (Eds.). (2000). From neurons to neighborhoods: The science of early childhood development. Washington, DC: National Academy Press.

Snook, S. C., \& Gorsuch, R. L. (1989). Component analysis versus common factor analysis: A Monte Carlo study. Psychological Bulletin, 106(1), 148-154.

Sroufe, L. A. (1997). Psychopathology as an outcome of development. Development \& Psychopathology, 9(2), 251-268.

Stollar, S. A., \& Dye Collins, P. A. (1994). Structured free-play to reduce disruptive activity changes in a head start classroom. School Psychology Review, 23(2), 310-323.

Swartz, J. L., \& Martin, W. E. J. (Eds.). (1997). Applied ecological psychology for schools within communities: Assessment and intervention. Mahwah, NJ: Lawrence Erlbaum Associates.

U.S. Department of Health and Human Services. (1997). Program performance standards for the operation of Head Start programs by grantee and delegate agencies, 45 C.F.R. Part 1304, Federal Register, 61, 57186-57227. Washington, DC: U.S. Government Printing Office. 
U.S. Department of Health and Human Services (USDHHS). (2001). Report of the Surgeon General's Conference on Children's Mental Health: A National Action Agenda. Washington, DC: U.S. Department of Health and Human Services.

U.S. Department of Health and Human Services (USDHHS). (2002). Early childhood education and school readiness: Conceptual models, constructs, and measures. Retrieved December 1, 2003, from http://www.nichd.nih.gov/crmc/cdb/Kyle-workshop.pdf Velicer, W. F. (1976). Determining the number of components from the matrix of partial correlations. Psychometrika, 41(3), 321-327.

Wachs, T. D. (1992). The nature of nurture. Newbury Park, CA: Sage.

Yates, A. (1987). Multivariate exploratory data analysis: A perspective on exploratory factor analysis. Albany, NY: SUNY Press. 


\section{Authors Note}

This research project was supported by a Head Start Graduate Student Research Scholars grant to the first author and a Head Start/University Partnerships grant to the second and third authors from the U.S. Department of Health and Human Services. A special thank you goes to our collaborators at Prekindergarten Head Start in the School District of Philadelphia: Directors Jennifer Plumer Davis and David Silbermann, Assistant Director, Dr. Stephanie Childs, Special Needs Coordinator Samuel Mosca, Head Start teacher, Judy McDowell, and Education Field Coordinators, Head Start teachers and teacher assistants. Many thanks also to members of the Research Team at the University of Pennsylvania for all their assistance and collegial support in preparation of this manuscript. Correspondence concerning this article should be addressed to the first author at The Herr Research Center for Children and Social Policy, Erikson Institute, 420 North Wabash, Chicago, IL 60611 or via email at rshearer@erikson.edu. 


\section{Footnotes}

${ }^{1}$ The less than $50 \%$ prevalence distinction was made in the nationally representative study of the ASCA syndromes (McDermott \& Schaefer, 1996) and in the construct validation study of the ASPI behavioral dimensions (Lutz et al., 2002). Because prevalence may vary significantly as a function of developmental level, sex, ethnicity, and socioeconomic status, latent problem dimensions that are generalizable across diverse groups of children should be based on both rare (essentially prevalence levels less than $2.1 \%$ ) and common (prevalence levels greater than 2.1 and less than 50\%) problem behaviors. This guideline parallels the basic measurement principle, that scale discrimination or test discrimination for external criteria must rely on acceptable item variability (item-total $r$ s between .20 and .80 ). This variability enables the different item dimensions to relate differentially to external criteria (in this case, situational dimensions of problem behavior) while still maintaining internal consistency (relative homogeneity among items) (Allen \& Yen, 1979).

${ }^{2}$ Since there were a variable number of items comprising each situation, raw scores totals for each of the 22 situations were scaled so that the situations would be comparable and equitably subjected to factor analytic procedures.

${ }^{3}$ Structural invariance was examined by repeating common-factor analysis with the final solution across 12 random subsamples (i.e., subsamples included 6 pairs of mutually exclusive halves of the original sample, $n=1,500)$. Generalizability was investigated in the same manner, repeating the analyses for independent subsamples based on child age, sex and ethnicity. The solution derived from each analysis was compared with that for the full sample using WrigleyNeuhaus coefficients of congruence based on all obtained loadings (Guadagnoli \& Velicer, 
1991). The coefficients assess the extent to which the solution established for the larger population could adequately represent solutions unique to the subgroups.

${ }^{4}$ Effect sizes $=.50, .20$, and .26 for significant differences between three-year-olds vs. four-year-olds across Structured Learning, Peer Interaction, and Teacher Interaction, respectively as calculated by Hedge's g (Cooper \& Hedges, 1994). Effect sizes $=.62, .25$, and .43 for comparison of three-year-olds vs. five-year-olds across Structured Learning, Peer Interaction, and Teacher Interaction, respectively. Effect sizes $=.15$ and .18 for comparison across Structured Learning and Teacher Interaction, for comparison of four-year-olds vs. five-year-olds respectively. Effect sizes $=.31, .32$, and .13 for comparison of boys vs. girls across Structured Learning, Peer Interaction, and Teacher Interaction, respectively as calculated by Hedge's g (Cooper \& Hedges, 1994).

${ }^{5}$ Hierarchical Linear Modeling was considered at the outset of the study due to the shared classroom-level variance in the outcome models. However, HLM was not chosen as a data analytic strategy because there was not sufficient variability at each classroom level to employ a multilevel approach, particularly for the COR outcome sample $(N=482)$ since the outcome sample was chosen to be geographically representative of the prekindergarten Head Start program. Over $30 \%$ of the classrooms represented in this sample contained less than 10 children (almost $25 \%$ of these contained less than 4 children per classroom). HLM indirect estimators are fully dependent on the number of observations within clusters (classrooms). Since this study was exploratory in nature the multivariate hierarchical setwise regression models fit the study's intended purpose. Future studies such as those conducted nationally with the ASPI (e.g., Head Start Impact Study) will provide the opportunity to replicate this study with a larger nationallyrepresentative sample. 
Table 1

Exploratory and Confirmatory Structures of ASPI Situational Dimensions

\begin{tabular}{|c|c|c|c|c|}
\hline \multirow[b]{2}{*}{$\begin{array}{l}\text { Situational Dimension } \\
\text { and Component Situations }\end{array}$} & \multicolumn{2}{|c|}{$\begin{array}{l}\text { Exploratory } \\
\text { Analyses }\end{array}$} & \multicolumn{2}{|c|}{$\begin{array}{c}\text { Confirmatory } \\
\text { Analyses }\end{array}$} \\
\hline & $\begin{array}{l}\text { Promax } \\
\text { loading }^{\mathrm{a}}\end{array}$ & $\begin{array}{l}\text { Equamax } \\
\text { loading }\end{array}$ & $\begin{array}{l}R^{2} \text { with own/ } \\
\text { next dimension }\end{array}$ & $\begin{array}{l}\text { Structure } \\
\text { loading }\end{array}$ \\
\hline \multicolumn{5}{|l|}{ Problems in Structured Learning } \\
\hline Involvement in Class Activities & .60 & .50 & .45 & .67 \\
\hline Taking Part in Games with Others & .57 & .52 & .55 & .74 \\
\hline Maintaining Companions/Friends & .57 & .44 & .35 & .59 \\
\hline Paying Attention in Class & .57 & .53 & .57 & .75 \\
\hline Sitting Teacher-Directed Activities & .55 & .53 & .57 & .76 \\
\hline Free Play/Individual Choice & .55 & .53 & .60 & .77 \\
\hline Working with Hands (Art) & .51 & .47 & .47 & .69 \\
\hline \multicolumn{5}{|l|}{ Problems in Peer Interaction } \\
\hline Getting along with Agemates & .71 & .65 & .56 & .75 \\
\hline Behaving in Classroom & .66 & .66 & .65 & .80 \\
\hline Respect for Others' Belongings & .65 & .61 & .51 & .71 \\
\hline Reaction to Correction & .61 & .61 & .58 & .76 \\
\hline Telling the Truth & .60 & .48 & .32 & .57 \\
\hline Standing in Line & .49 & .55 & .52 & .72 \\
\hline
\end{tabular}

(continued) 


\begin{tabular}{|c|c|c|c|c|}
\hline \multirow[b]{2}{*}{$\begin{array}{l}\text { Situational Dimension } \\
\text { and Component Situations }\end{array}$} & \multicolumn{2}{|c|}{$\begin{array}{l}\text { Exploratory } \\
\text { Analyses }\end{array}$} & \multicolumn{2}{|c|}{$\begin{array}{l}\text { Confirmatory } \\
\text { Analyses }\end{array}$} \\
\hline & $\begin{array}{l}\text { Promax } \\
\text { loading }^{\text {a }}\end{array}$ & $\begin{array}{l}\text { Equamax } \\
\text { loading }\end{array}$ & $\begin{array}{l}R^{2} \text { with own/ } \\
\text { next dimension }\end{array}$ & $\begin{array}{l}\text { Structure } \\
\text { loading }\end{array}$ \\
\hline \multicolumn{5}{|l|}{ Problems in Teacher Interaction } \\
\hline Talking to Teacher & .68 & .41 & .56 & .75 \\
\hline General Manner with Teacher & .65 & .65 & .55 & .74 \\
\hline Answering Teacher Questions & .48 & .50 & .47 & .68 \\
\hline Greeting Teacher & .42 & .41 & .33 & .58 \\
\hline Seeking Teacher Help & .41 & .45 & .37 & .61 \\
\hline Helping Teacher with Jobs & .40 & .42 & .37 & .61 \\
\hline
\end{tabular}

$N=3779$. ASPI= Adjustment Scales for Preschool Intervention.

${ }^{a}$ Entries are derived from promaxian oblique rotation at $k=4$ with the equamax structure matrix serving as the initial orthogonal structure.

${ }^{\mathrm{b}}$ Entries are based on oblique, principal-components, cluster analysis (Anderberg, 1973; Harman, 1976), where hypothesized situationdimension membership is determined through prior exploratory factoring. $R^{2}$ for a situation's own dimension indicates the proportion of a situation's variance predicted by other situations in the hypothesized correct dimension, whereas $R^{2}$ for a situation's next dimension indicates variance predicted by situations in the alternative dimensions. 


\section{Table 2}

Generality and Invariance of ASPI Situational Dimensions

Generality

\begin{tabular}{|c|c|c|c|c|c|c|c|c|}
\hline \multirow[b]{2}{*}{ Situational Dimension } & \multirow[b]{2}{*}{ Invariance $^{a}$} & \multirow[b]{2}{*}{$\begin{array}{l}\text { Younger }^{\mathrm{b}} \\
n=1747\end{array}$} & \multirow[b]{2}{*}{$\begin{array}{c}\text { Older } \\
n=1790\end{array}$} & & & & & \\
\hline & & & & $\begin{array}{c}\text { Male } \\
n=1710\end{array}$ & $\begin{array}{c}\text { Female } \\
n=1813\end{array}$ & $\begin{array}{l}\text { African- } \\
\text { American } \\
n=2494\end{array}$ & $\begin{array}{c}\text { Hispanic } \\
n=544\end{array}$ & $\begin{array}{l}\text { Other }^{\mathrm{d}} \\
n=350\end{array}$ \\
\hline Problems in Structured Learning & g $98(20)$ & $98(21)$ & $80(32)$ & $78(39)$ & $96(18)$ & $96(20)$ & $97(21)$ & $81(33)$ \\
\hline Problems in Peer Interaction & $99(14)$ & $99(07)$ & $97(18)$ & $97(03)$ & $99(17)$ & $99(14)$ & $98(10)$ & $95(02)$ \\
\hline Problems in Teacher Interaction & $99(12)$ & 99 (14) & $93(06)$ & $91(19)$ & $98(10)$ & $99(11)$ & $98(15)$ & 89 (19) \\
\hline Average & $99(15)$ & 99 (14) & $97(19)$ & $97(20)$ & $99(15)$ & $99(15)$ & $99(15)$ & $88(18)$ \\
\hline
\end{tabular}

Note. ASPI = Adjustment Scales for Preschool Intervention. Entries are Wrigley-Neuhaus coefficients (Guadagnoli \& Velicer, 1991) with decimals omitted for convenient presentation. Nonparenthetical values indicate similarity of the respective factor extracted from the full national standardization sample to the counterpart dimension extracted for a given subsample. Parenthetical values indicate average similarity of the specified dimension to all other (noncounterpart) dimensions extracted from the subsample. Factor analyses for subsamples proceeded exactly as that for the full national sample.

\footnotetext{
${ }^{a}$ Coefficients are averages of 12 random subsamples ( $n=1500$ each) compared to the solution for the full sample.

${ }^{\mathrm{b}}$ Composed of children equal to or younger than the full sample median age of 4.35 years.

${ }^{c}$ Composed of children older than the full sample median age of 4.35 years.

${ }^{\mathrm{d}}$ Composed of children of the following ethnicities: White, Asian, Native American and other.
} 


\section{Table 3}

Internal Consistency of ASPI Situational Dimensions

Internal consistency $^{\text {a }}$

\begin{tabular}{|c|c|c|c|c|c|c|c|c|}
\hline $\begin{array}{l}\text { Situational } \\
\text { Dimension }\end{array}$ & $\begin{array}{c}\text { Total } \\
N=3779\end{array}$ & $\begin{array}{c}\text { Males } \\
n=1710\end{array}$ & $\begin{array}{c}\text { Females } \\
n=1813\end{array}$ & $\begin{array}{c}\text { African- } \\
\text { American } \\
n=2494\end{array}$ & $\begin{array}{c}\text { Hispanic } \\
n=544\end{array}$ & $\begin{array}{l}\text { Other }^{\mathrm{b}} \\
n=350\end{array}$ & $\begin{array}{c}\text { Younger }^{\mathrm{c}} \\
n=1747\end{array}$ & $\begin{array}{l}\text { Older }^{\mathrm{d}} \\
n=1790\end{array}$ \\
\hline Problems in Structured Learning & .84 & .84 & .83 & .83 & .85 & .83 & .84 & .81 \\
\hline Problems in Peer Interaction & .81 & .82 & .78 & .81 & .83 & .76 & .81 & .81 \\
\hline Problems in Teacher Interaction & .75 & .75 & .74 & .74 & .77 & .77 & .76 & .73 \\
\hline Average & .80 & .80 & .78 & .79 & .82 & .79 & .80 & .78 \\
\hline
\end{tabular}

Note. ASPI $=$ Adjustment Scales for Preschool Intervention

${ }^{\text {a }}$ Values are coefficient alpha computed for each subgroup of children.

${ }^{b}$ The subsample included children of the following ethnicities: White, Asian, Native American, and other.

${ }^{\mathrm{c}}$ The subsample included children equal or younger than the full sample median age (4.35 years).

${ }^{\mathrm{d}}$ The subsample included children older than the full sample median age (4.35 years). 


\section{Table 4}

Group Means and Standard Deviations for ASPI Situational Dimensions by Child Age and Sex

\begin{tabular}{|c|c|c|c|c|c|c|c|c|}
\hline & \multicolumn{2}{|c|}{ Three-year-olds ${ }^{\mathrm{a}}$} & \multicolumn{3}{|c|}{ Four-year-olds } & \multicolumn{3}{|c|}{ Five-year-olds } \\
\hline & Male & Female & Male & Femal & & Male & Femal & \\
\hline ASPI Situational Dimension & $n=496$ & $n=548$ & $n=1059$ & $n=113$ & & $n=155$ & $n=128$ & \\
\hline Problems in Structured Learning & $55.36(10.22)$ & $51.99(10.05)$ & $50.32 \quad(9.76)$ & 47.30 & $(8.96)$ & $48.87 \quad(8.98)$ & 45.63 & $(7.59)$ \\
\hline Problems in Peer Interaction & $53.65(10.33)$ & $49.61 \quad(9.59)$ & $51.04(10.44)$ & 48.16 & $(9.21)$ & $50.44(10.58)$ & 47.31 & $(9.09)$ \\
\hline Problems in Teacher Interaction & $52.72(10.44)$ & $51.42(10.50)$ & $50.03(10.14)$ & 48.84 & $(9.61)$ & $49.06 \quad(9.43)$ & 45.95 & $(9.20)$ \\
\hline
\end{tabular}

Note. $N=3779$.

${ }^{a}$ Values are means and $(S D)$ computed for each subgroup of children for standardized $\mathrm{T}$ scores created based on a normative sample of low-income, preschool children. 
Table 5

Unique Contribution of ASPI Behavioral and Situational Dimensions to Interactive Peer Play Outcomes

\begin{tabular}{|c|c|c|c|}
\hline & \multicolumn{3}{|c|}{ Interactive Peer Play (PIPPS) } \\
\hline & Play & Play & Play \\
\hline & Disconnection & Disruption & Interaction \\
\hline \multicolumn{4}{|l|}{$\%$ Variance explained by: } \\
\hline Child demographics & $2.8 * *$ & $3.7 * * * *$ & $13.6 * * * *$ \\
\hline Behavioral dimensions & $3.0 * * * *$ & $39.5 * * * *$ & $19.3 * * * *$ \\
\hline Situational dimensions ${ }^{\text {a }}$ & $21.3 * * * *$ & $0.7^{*}$ & $2.5 * * * *$ \\
\hline Overall Model $^{\mathrm{b}}$ & $28.6 * * * *$ & $44.0 * * * *$ & $36.7 * * * *$ \\
\hline \multicolumn{4}{|l|}{$N=707$} \\
\hline \multicolumn{4}{|c|}{$* p<.05, * * p<.01, * * * p<.001, * * * * p<.0001$} \\
\hline \multicolumn{4}{|c|}{$\begin{array}{l}{ }^{\text {a }} \text { Values equal the partial } R^{2}(100) \text { for prediction of PIPPS dimensions uniquely by situational } \\
\text { dimensions controlling (accounting for) the variance explained by the behavioral dimensions and } \\
\text { by demographic covariates. }\end{array}$} \\
\hline
\end{tabular}


Table 6

Multivariate Hierarchical Setwise Regression of ASPI Behavioral and Situational Dimensions Predicting Interactive Peer Play

\begin{tabular}{lccc}
\hline & \multicolumn{3}{c}{ Interactive Peer Play (PIPPS) ${ }^{\text {a } b}$} \\
\cline { 2 - 4 } & Play & Play \\
& Disconnection & Disruption & Play \\
& $\beta$ & $\beta$ & $\beta$ \\
\hline Variable & & & \\
\hline
\end{tabular}

Child demographic variables $^{\mathrm{c}}$

Behavioral dimensions

Aggressive $-0.27$

0.24

0.14

Inattentive/Hyperactive

$-0.13 *$

0.08

$0.13 * *$

Oppositional

$0.58 *$

$0.61 *$

$-0.89 * * *$

Withdrawn/Low Energy

$-0.01$

$-0.10 *$

$-0.09$

Socially Reticent

$0.56 * *$

0.05

$-0.24$

\section{Situational dimensions}

Structured Learning

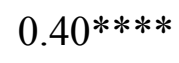

$-0.01$

$-0.29 * * * *$

Peer Interaction

$0.58 *$

$0.57 *$

$-0.27$

Teacher Interaction

0.57

$-0.01$

$-0.67 *$

Pheno. \& Situational Interaction

Socially Reticent \& Teacher Inter.

$-0.79^{*}$

$-0.11$

0.21

Oppositional \& Peer Inter.

$-0.80$

$-0.78 *$

0.45

Oppositional \& Teacher Inter.

$-0.40$

$-0.16$

$1.34 * *$

$N=707$. 
${ }^{a}$ Prior to being entered in the regression model, measures were standardized as T scores based on a normative sample of low-income, preschool children.

${ }^{b}$ Entries are standardized parameter estimates derived in multivariate hierarchical multiple regression. All values reflect the relative contribution of each dimension on the PIPPS dependent variable (controlling for child age, sex, and ethnicity, and all other behavioral and situational dimensions). Tests assess the deviation of each parameter estimate from zero, where $* p<.05$, $* * p<.01, * * * p<.001, * * * * p<.0001$. Note that $B$ and $S E B$ are listed in Appendix B1.

${ }^{\mathrm{c}}$ For the sake of parsimony, regression weights for demographic covariates are not presented in this table. Significant values were found in the prediction of Play Interaction: age $(\beta=0.17, p<$ $.0001), \operatorname{sex}(\beta=0.15, p<.0001)$, white $(\beta=0.11, p<.05)$, and hispanic variables $(\beta=0.09, p<$ $.05)$. 
Table 7

Unique Contribution of ASPI Behavioral and Situational Dimensions to Classroom Learning Outcomes

\begin{tabular}{|c|c|c|c|}
\hline & \multicolumn{3}{|c|}{ Child Observation Record (COR) } \\
\hline & $\begin{array}{l}\text { Cognitive } \\
\text { Skills }\end{array}$ & $\begin{array}{c}\text { Social } \\
\text { Engagement }\end{array}$ & $\begin{array}{c}\text { Movement } \\
\& \text { Coordination }\end{array}$ \\
\hline \multicolumn{4}{|l|}{$\%$ Variance explained by: } \\
\hline Child demographics & $25.7 * * * *$ & $13.3^{* * * *}$ & $12.2 * * * *$ \\
\hline Behavioral dimensions & 1.2 & $21.4 * * *$ & $2.7 * *$ \\
\hline Situational dimensions $^{\mathrm{a}}$ & $11.5 * * * *$ & $1.7 * *$ & $18.0 * * * *$ \\
\hline Overall model $^{\mathrm{b}}$ & $39.0 * * * *$ & $38.6 * * * *$ & $34.3 * * * *$ \\
\hline \multicolumn{4}{|l|}{$N=478$} \\
\hline \multicolumn{4}{|c|}{${ }^{*} p<.05, * * p<.01, * * * p<.001, * * * * p<.0001$} \\
\hline \multicolumn{4}{|c|}{$\begin{array}{l}{ }^{\text {a }} \text { Values equal the partial } R^{2}(100) \text { for prediction of COR dimensions uniquely by situational } \\
\text { dimensions controlling (accounting for) the variance explained by the behavioral dimensions and } \\
\text { demographic covariates. }\end{array}$} \\
\hline
\end{tabular}


Table 8

Multivariate Hierarchical Setwise Regression of ASPI Behavioral and Situational Dimensions

Predicting Classroom Learning Outcomes

\begin{tabular}{lccc}
\hline & \multicolumn{3}{c}{ Child Observation Record (COR) ${ }^{\mathrm{a} b}$} \\
\cline { 2 - 4 } & $\begin{array}{c}\text { Cognitive } \\
\text { Skills }\end{array}$ & $\begin{array}{c}\text { Social } \\
\text { Engagement }\end{array}$ & $\begin{array}{c}\text { Movement } \\
\text { \& Coordination }\end{array}$ \\
\hline Variable & $\beta$ & $\beta$ & $\beta$ \\
\hline
\end{tabular}

Child demographic variables $^{\mathrm{c}}$

Behavioral dimensions

Aggressive

0.26

0.56

$-0.12$

Inattentive/Hyperactive

$-0.53$

$-0.78 * *$

$-0.58$

Oppositional

0.03

0.10

0.11

Withdrawn/Low Energy

$-0.12 *$

$-0.19 * *$

$-0.17 * *$

Socially Reticent

$-0.30$

$-0.61 * *$

$-0.27$

Situational dimensions

Structured Learning

$-0.96 * *$

$-1.11 * * *$

$-0.81 *$

Peer Interaction

$-0.02$

$-0.05$

$-0.53$

Teacher Interaction

0.31

0.16

0.18

Pheno. \& Situational Interaction

Socially Reticent \& Struc. Learn.

$1.22 *$

$1.45 * *$

0.96

Inatten/Hyper. \& Peer Inter.

.90

$1.45 * *$

0.92

$N=478$.

${ }^{a}$ Prior to being entered in the regression model, measures were standardized as $\mathrm{T}$ scores based on a normative sample of low-income, preschool children. 
${ }^{\mathrm{b}}$ Entries are standardized parameter estimates derived in hierarchical multiple regression of the COR dimensions on the behavioral and situational dimensions. Values reflect the relative contribution of each dimension as covaried by child age, sex, and ethnicity, and all other behavioral and situational dimensions. Tests assess the deviation of each parameter estimate from zero, where ${ }^{*} p<.05, * * p<.01, * * * p<.001, * * * * p<.0001$. Note that $B$ and $S E B$ are listed in Appendix B2.

${ }^{\mathrm{c}}$ For the sake of parsimony, regression weights for demographic covariates are not presented in this table. Age was the only significant demographic variable in this model, with: $(\beta=0.40, p<$ $.0001),(\beta=0.21, p<.0001)$, and $(\beta=0.18, p<.0001)$ for the prediction of Cognitive, Social, and Movement \& Coordination dimensions respectively. 
Table 9

Combined Contribution of ASPI Behavioral and Situational Dimensions to Interactive Peer Play Outcomes

\begin{tabular}{|c|c|c|c|}
\hline & \multicolumn{3}{|c|}{ Interactive Peer Play (PIPPS) } \\
\hline & Play & Play & Play \\
\hline & Disconnection & Disruption & Interaction \\
\hline \multicolumn{4}{|l|}{$\%$ Variance explained by: } \\
\hline Child demographics & $2.8^{* *}$ & $3.7 * * * *$ & $13.6 * * * *$ \\
\hline Situational $^{\mathrm{a}}$ & $21.3 * * * *$ & $32.1 * * * *$ & $17.7 * * * *$ \\
\hline Behavioral $^{\mathrm{b}}$ & $20.8 * * * *$ & $39.5 * * * *$ & $19.3 * * * *$ \\
\hline Situational and Behavioral $^{\mathrm{c}}$ & $24.3 * * * *$ & $39.8 * * * *$ & $21.2 * * * *$ \\
\hline Overall model $^{\mathrm{d}}$ & $28.6^{* * * *}$ & $44.0 * * * *$ & $36.7 * * * *$ \\
\hline \multicolumn{4}{|l|}{$N=707$} \\
\hline \multicolumn{4}{|c|}{$\begin{array}{l}{ }^{a} \text { Values equal the partial } R^{2}(100) \text { for prediction of PIPPS dimensions by situational dimensions } \\
\text { alone as a set, controlling (accounting for) the variance explained by demographic covariates. }\end{array}$} \\
\hline \multicolumn{4}{|c|}{$\begin{array}{l}{ }^{\mathrm{b}} \text { Values equal the partial } R^{2}(100) \text { for prediction of PIPPS dimensions by behavioral dimensions } \\
\text { alone as a set, controlling (accounting for) the variance explained by demographic covariates. }\end{array}$} \\
\hline \multicolumn{4}{|c|}{$\begin{array}{l}{ }^{\mathrm{c}} \text { Values equal the partial } R^{2}(100) \text { for prediction of PIPPS dimensions by both behavioral and } \\
\text { situational dimensions combined together as a set, controlling (accounting for) the variance } \\
\text { explained by demographic covariates. }\end{array}$} \\
\hline
\end{tabular}


Table 10

Combined Contribution of ASPI Behavioral and Situational Dimensions to Classroom Learning Outcomes

\section{Child Observation Record (COR)}

\begin{tabular}{ccc}
\hline Cognitive & Social & Movement \\
Skills & Engagement & \& Coordination
\end{tabular}

$\%$ Variance explained by:

Child demographics

$25.7 * * * *$

Situational $^{\mathrm{a}}$

Behavioral $^{\mathrm{b}}$

Situational and Behavioral ${ }^{\mathrm{c}}$

Overall model $^{\mathrm{d}}$
$11.5 * * * *$

$10.7 * * * *$

$12.1 * * * *$

$39.0 * * * *$
$13.3 * * * *$

$20.3 * * * *$

$21.4 * * * *$

$23.1 * * * *$

$38.6 * * * *$
$12.2 * * * *$

$18.0 * * * *$

$18.8^{* * * *}$

$20.7 * * * *$

$34.3 * * * *$

$N=478$.

${ }^{\text {a }}$ Values equal the partial $R^{2}(100)$ for prediction of COR dimensions by situational dimensions alone as a set, controlling (accounting for) the variance explained by demographic covariates.

${ }^{\mathrm{b}}$ Values equal the partial $R^{2}(100)$ for prediction of COR dimensions by behavioral dimensions alone as a set, controlling (accounting for) the variance explained by demographic covariates.

${ }^{\mathrm{c}}$ Values equal the partial $R^{2}$ (100) for prediction of COR dimensions by both behavioral and situational dimensions combined together as a set, controlling (accounting for) the variance explained by demographic covariates.

${ }^{\mathrm{d}}$ Values equal the multiple $R^{2}(100)$ for prediction of COR dimensions for the entire model. 


\section{Appendix A1 \\ Adjustment Scales for Preschool Intervention (ASPI) Classroom Situations}

1. How does this child greet you as the teacher?

2. How does this child help with jobs?

3. How does this child answer questions?

4. How does this child seek your help?

5. How does this child talk with you?

6. How does this child seem to value attention?

7. What is this child's general manner with you?

8. How does this child behave in the classroom?

9. Is this child truthful?

10. How does this child react to correction?

11. Does this child pay attention in the classroom?

12. How does this child cope with new learning tasks?

13. How does this child get involved in classroom activities?

14. How does this child work with hands (artwork, etc.)?

15. How does this child sit during class-wide, teacher directed activities (e.g., story time, circle time, etc.)?

16. Does this child respect other people's belongings?

17. How does this child take part in games with other children?

18. How is this child at free play/individual choice?

19. Whom does this child have as his/her companions?

20. How does this child behave when standing in line?

21 . How does this child get along with others of his/her age?

22. How does this child handle conflicts with other children? 


\section{Appendix A2}

\section{ASPI Directions and two sample classroom situations with behavioral descriptions}

Directions: After each question, there are several descriptions of behaviors children may display. Fill in the circle beside any description that fits the child's behavior over the past month. For each question, mark as many descriptions as apply to the child. If no descriptions apply, then do not fill in any circles for that question.

\section{A.1. Sample 1: How does this child cope with new learning tasks?}

- Has a happy-go-lucky attitude to every problem

- Charges in without taking time to think or follow instructions

- Approaches new tasks with caution, but tries

- Won't even attempt it if he/she senses a difficulty

- Likes the challenge of something difficult

- Cannot work up the energy to face anything new

\section{A.2. Sample 2: How is this child at free play/individual choice?}

- Engages in appropriate activities

- Rather loud but not disruptive

- Is too timid to join in

- Disturbs others' fun

- Wants to dominate and have his/her own way

- Starts fights and rough play

- Needs teacher assistance to get involved

- Usually plays by him/herself

- Moves quickly from one activity to another 


\section{Appendix B1}

Multivariate Hierarchical Setwise Regression for ASPI Behavioral and Situational Dimensions Predicting Interactive Peer Play

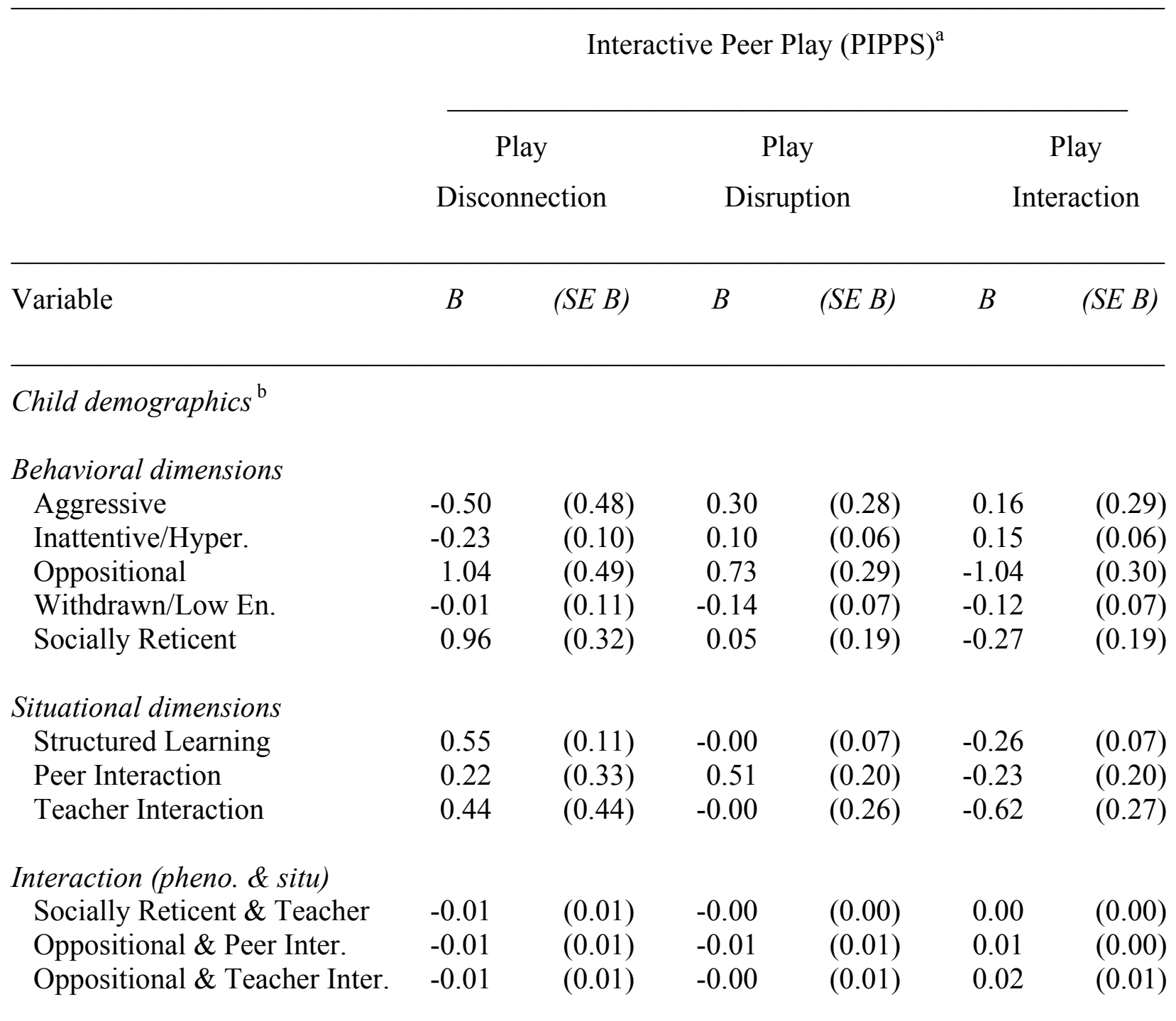

$N=707$.

${ }^{a}$ Entries are unstandardized parameter estimates $(B)$ and standard errors for the estimate (SE $\left.B\right)$ derived in multivariate hierarchical multiple regression. All values are covaried by child age, sex, and ethnicity, and all other behavioral and situational dimensions.

${ }^{\mathrm{b}}$ For the sake of parsimony, regression weights for demographic covariates are not presented. Significant values were found in the prediction of Play Interaction: age $(B=2.86, S E B=0.53)$, $\operatorname{sex}(B=3.00, S E B=0.62)$, white $(B=2.99, S E B=1.37)$, and hispanic variables $(B=3.31, S E$ $B=1.54)$. 
Appendix B2

Multivariate Hierarchical Setwise Regression of ASPI Behavioral and Situational Dimensions Predicting Classroom Learning Outcomes

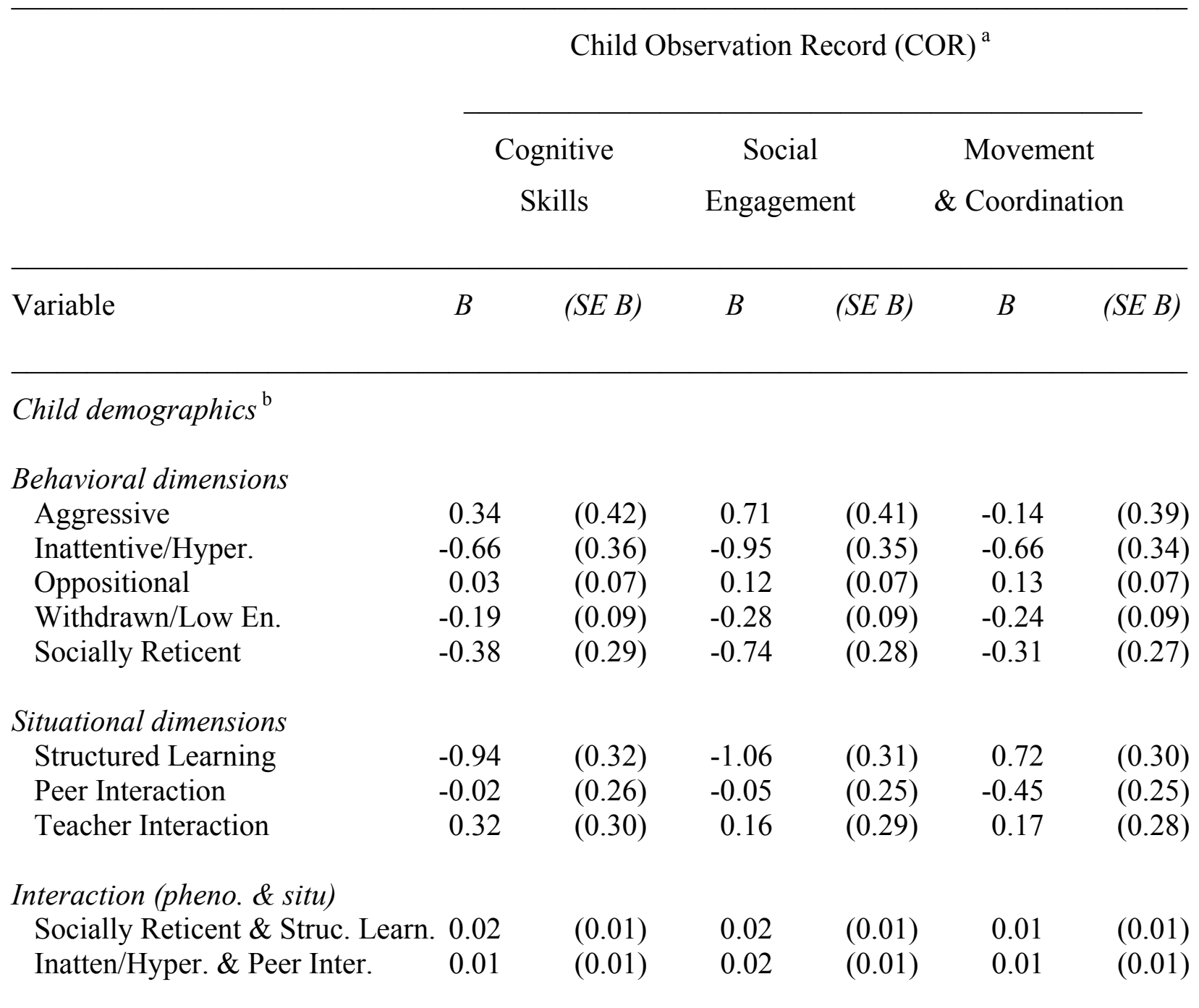

$N=478$.

${ }^{a}$ Entries are unstandardized parameter estimates $(B)$ and standard errors for the estimate $(S E B)$ derived in multivariate hierarchical multiple regression. All values are covaried by child age, sex, and ethnicity, and all other behavioral and situational dimensions.

${ }^{\mathrm{b}}$ For the sake of parsimony, regression weights for demographic covariates are not presented in this table. Age was the only significant demographic predictor in this model, with: $(B=7.45, S E$ $B=0.73),(B=3.82, S E B=0.71)$, and $(B=3.07, S E B=0.69)$ for the prediction of Cognitive, Social, and Movement \& Coordination dimensions, respectively. 


\section{Appendix $\mathrm{C}$}

Bivariate Correlations between Fall ASPI Behavioral and Situational Variables and Peer Social and Classroom Learning Competencies at the End of the Year

\begin{tabular}{|c|c|c|c|c|c|c|}
\hline \multirow[b]{2}{*}{ Fall ASPI Variables } & \multicolumn{5}{|c|}{ Spring Competency Outcomes } & \multirow[b]{2}{*}{$\begin{array}{c}\text { Coordinated } \\
\text { Movement }\end{array}$} \\
\hline & $\begin{array}{c}\text { Play } \\
\text { Disconnection }\end{array}$ & $\begin{array}{c}\text { Play } \\
\text { Disruption }\end{array}$ & $\begin{array}{c}\text { Play } \\
\text { Interaction }\end{array}$ & $\begin{array}{l}\text { Cognitive } \\
\text { Skills }\end{array}$ & $\begin{array}{c}\text { Social } \\
\text { Engagement }\end{array}$ & \\
\hline \multicolumn{7}{|l|}{ Behavioral dimensions } \\
\hline Aggressive & $.16^{* * * *}$ & $.63^{* * * *}$ & $-.22 * * * *$ & $-.17 * * *$ & $-.16^{* * *}$ & $-.09 *$ \\
\hline Inattentive/Hyperactive & $.15 * * * *$ & $.47 * * * *$ & $-.16 * * * *$ & $-.23 * * * *$ & $-.21 * * * *$ & $-.20 * * * *$ \\
\hline Oppositional & $.15 * * * *$ & $.48 * * * *$ & $-.09 *$ & -.07 & -.05 & -.00 \\
\hline Withdrawn/Low Energy & $.35 * * * *$ & $-.13 * * *$ & $-.40 * * * *$ & $-.37 * * * *$ & $-.45 * * * *$ & $-.41 * * * *$ \\
\hline Socially Reticent & $.42 * * * *$ & -.06 & $-.41 * * * *$ & $-.33 * * * *$ & $-.44 * * * *$ & $-.39 * * * *$ \\
\hline \multicolumn{7}{|l|}{ Situational dimensions } \\
\hline Problems in Structured Learning & $.46^{* * * *}$ & $.33 * * * *$ & $-.49 * * * *$ & $-.43 * * * *$ & $-.48 * * * *$ & $-.42 * * * *$ \\
\hline Problems in Peer Interaction & $.24 * * * *$ & $.59 * * * *$ & $-.24 * * * *$ & $-.17 * * * *$ & $-.18 * * * *$ & $-.12 * *$ \\
\hline Problems in Teacher Interaction & $.38 * * * *$ & $.22 * * * *$ & $-.36^{* * * *}$ & $-.33 * * * *$ & $-.38 * * * *$ & $-.34 * * * *$ \\
\hline
\end{tabular}

$N=738,739,740$ for Play Disconnection, Play Disruption, Play Interaction, respectively.

$N=486,494,506$ for Cognitive Skills, Social Engagement, and Coordinated Movement, respectively 